\title{
Study of Temperature Distribution and Material Flow in Friction Stir Welding of AA6061-T6
}

\author{
Manoj Kumar ${ }^{1}$, Ramesh Kumar, ${ }^{2, *}$, and Sachin D Kore ${ }^{3}$ \\ ${ }^{1}$ Department of Mechanical Engineering, IIT Guwahati, Guwahati -781039, India \\ 2,Department of Mechanical Engineering, Saharsa College of Engineering, Saharsa, Bihar - 852201, India, \\ ${ }^{3}$ School of Mechanical Sciences, IIT Goa, Ponda- 403401, Goa, India \\ *Corresponding author. E-mail: remsiitg@gmail.com, Tel.: +91-9661494529, \\ ORCID ID: 0000-0001-5075-8360
}

\begin{abstract}
A fully-coupled 3-D model of FSW was developed for $4 \mathrm{~mm}$ plates of AA6061-T6 aluminum alloy based on the Finite Volume Method (FVM) in ANSYS Fluent 14.5 software. Two types of the model; one with the tool and another without tool was developed for different tool geometry and analysis was done for temperature distribution in the workpiece as well as in tool using system coupling for first model and workpiece only in later one. A parametric study was performed at different tool rotational speed regarding temperature distribution, and material flow analysis was carried out for all tool geometries at a single rotational speed. The material behaves differently when passes through the different tool and it was affected by thermal history, viscosity and strain rate for particular tool geometry. Temperature-dependent material properties and a user-defined function (UDF) code of viscosity have been incorporated in the model considering the workpiece as a non-Newtonian viscous fluid. A better material mixing observed in case of threaded pin geometry by using a steady-state laminar flow model. All tapered tool geometries were unable to mix material properly just below and around the pin tip due to very low-velocity magnitude in this region, which may lead to a kind of defect. An asymmetric temperature distribution observed in the workpiece and at higher rotational speed peak temperature observed higher in the workpiece, and the flow of heat was more in tool. Validation of the model was done by performing experiments.
\end{abstract}

Keywords: User-defined function, finite volume method, friction stir welding, temperature distribution, material flow

\section{INTRODUCTION}

The FSW primarily used for joining wrought aluminum, and the high weld strength is one of its primary benefits, which leads to the application on joining a particular structure which characteristics desire have strengthened weld. The aluminum has chosen primarily for FSW due to its lightweight and higher corrosion resistance towards the environment hence used in various sectors like shipbuilding, automotive, aerospace, etc. As the FSW is a solid-state welding technique, the temperature just below the melting temperature, but above the recrystallization temperature was achieved. This controlled temperature for welding achieved by the interaction between plates being to weld and suitable tool geometry, which generates enough frictional heat at the interface. Process parameters like welding speed, tool rotational speed, plunging pressure, etc. also play a vital role in heat generation. The significant heating at interface makes material soften, and it moves around the tool from advancing-front and deposits behind the tool along the weld line to complete the weld. 
Material flow behavior greatly affected by produced heat during the weld due to the coupled nature of this process, and coupled analysis is always challenging and more complex in a fluid flow problem. As the FSW well known for its high strength weld, it needs better mixing of material at the molecular level for healthy weld and consequently needs a tool having characteristics to the developed desired flow. Although a significant amount of experimental work has been done regarding material flow behavior, still it is more complex and difficult. Therefore, making of different complex tool design, a number of the experiment, wastage of material and consumption of valuable time can have reduced by the numerical simulation also instantaneous or snap shoot of particular weld region can be viewed easily.

The knowledge about the material flow under/around the tool requires an idea of thermal history in the weldment. The analogy of temperature distribution gives the knowledge that could be implemented in the material property. Treatment of solid as a fluid in this process gives an idea that a variable viscosity has required for the phase transition, which is surely dependent on temperature. Therefore, a lot of research has been done on various aspects of this process since the beginning of the year when FSW evolve, and the study of temperature distribution is one of them as it has prominent effects on material flow. Ulysse [1] was developed a numerical model based on the finite element method (FEM) of FSW in which AA 7050-T7451 considered as a workpiece and temperature distribution plotted along with the tool. It was observed that Pin force increase with increasing welding speed and the opposite effect observed for increasing rotational speed. In this study, a parametric studied also had done, and it was showed that welding temperature increased with rotational speed and decreased with welding speed. Meanwhile, Krishnan [2] describes a prominent feature of FSW experimentally that distance between the formations of two consecutive onion rings is equal to the forward movement of the tool in one rotation.

Modeling of tool motion as in real-world was difficult, which could make possible by Song and Kovacevic [3] with introducing the moving coordinate using finite difference method (FDM) and studied the heat generation in the transient 3-D model. In another work, Chen and Kovacevic [4] developed a 3-D FEM model for AA 6061-T6 in ANSYS and studied the effect of process parameters on residual stress and temperature distribution. A very complex study from the experiment point of view, i.e., material flow analysis of 6061, was done by Guerra et al. [5] using a threaded tool. Colegrove and Shecliff [6] derived the equation of viscosity depending upon normal stress and strain rate, a code of this equation given in ANSYS Fluent as input to develop a 3-D visco-plastic model of FSW for the analysis of material flow.

There were various models proposed in the early developing period of this process using various commercial software using the FEM and finite volume method (FVM) method. To replicate the real process or simulate the process as close as possible Buffa et al. [7] developed a finite element analysis (FEA) model on DEFORMED-3D commercial software in which tool has considered as a rigid body and workpiece assumed as a continuum, i.e., Lagrangian approached considered to model the FSW process. Material flow under the tool shoulder can be studied, making the use of the concept of fluid mechanics. Heurtier et al. [8] developed a threedimensional thermo-mechanical model based on the velocity classically used in fluid mechanics and considering heat input through the shoulder and material deformation; furthermore, the analysis was done for temperature and micro-hardness in the different weld zones. The properties of the welded joint directly rely on material flow. Metallography, X-ray, computed tomography (CT) and marker material techniques, etc. are the various method 
from which qualitative analysis of material flowing around the tool can be reviewed. These methods were used in literature by Schmidt et al. [9] for the material AA2024-T3.

The effect of tool geometries on heat generation and material flow were also studied experimentally as well as numerically. Different tool geometries help to achieved different temperatures and force the material to behave differently; also, a number of defects can be cured just by changing the tool geometry. Elangovan and Balasubramanian [10] studied the effect of pin profile and rotational speed of tool on the weld zone for AA2219 aluminum alloy performing the tensile test and analyzing friction stir processed (FSP) zone macroscopically. In a further development of this process, Nandan et al. [11] bridges the gap and moves close to the real process by modeling FSW of mild steel and studied the material flow and heat transfer in detail. In a paper by Chen et al. [12] flow of shear zone around the tool and how it deposited in the trailing side to form the nugget zone was describing briefly.

(2) Hao su et al. [17] developed a numerical method based on computational fluid dynamics and quantitatively analyse the thermo-physical phenomena in friction stir welding with two tools of different pin shapes (axisymmetrical conical tool and asymmetrical triflat tool). It was observed that The heat density at the pin side flat area is slightly lower that at the pin side arc area of TT and the pin side of CT. No significant differences of total heat generation, heat density at the shoulder-workpiece interface and temperature profile are found for the two tools (CT and TT). It is found that the "stir action" of TT is more drastic than that of CT. The pin side flat area changes the distribution feature of strain rate and viscosity, and enlarges the deformation region. Although, in many literatures there have been no significant differences observed of total heat generation but significant changes observed for heat flux for different tool geometries which affect the material flow behaviour.

Z. Sun and C. S. Wu [18] best described this feature for threaded pin and reported the comparisons of heat flux at $2 \mathrm{~mm}$ below the shoulder surface.

Hao su et al. [19] proposed a numerical model for the optimization design of tool pin profile starting with circular pin and designing the three flat with different angle ending with triangular pin that identifying different torque components on flat area, and also considering the material flow behavior and tool wear tendency. The thermal response, material flow behavior and welding loads are analyzed for all five pin profile with different proportion of flat surfaces. The numerical model is verified by comparing the results with measured thermal cycle, macrostructure, tool torque, and traverse force for both tool pins with and without flat feature.

Very few works reported that the tool had included instead of tool impression wall when model developed in ANSYS Fluent. In this present work, two models have developed, one incorporating the tool and another impression wall. Six tool geometries considered for the analysis of material flow along with temperature distribution. Out of which two of the tool geometries considered for temperature distribution in the workpiece as well as in the tool itself. Also, the study of viscosity distribution, strain rate distribution, and deformation zone created by the tool in the weld zone by vector plots and velocity contours have studied for all tool geometries. The analysis was done using a steady-state and laminar model with all variable thermal property assigned for AA6061T6 in ANSYS Fluent 14.5. Experiments have conducted and temperature profiles compared to validate the proposed models. 


\section{MODEL DESCRIPTION}

In this present work, aluminum alloy AA6061-T6 plates were considered for finite volume modeling of FSW. Different tool geometries were used to weld two separates plates together having dimensions $175 \times 50 \times 4$ $\mathrm{mm}^{3}$. The shoulder size $(24 \mathrm{~mm})$ and pin length $(3.2 \mathrm{~mm})$ for all tool geometries were kept constant. All type of tool pin was made within a standard frustum having major and minor diameter is $9 \mathrm{~mm}$ and $7 \mathrm{~mm}$ respectively.

Two types of models, i.e., Model-1 (with tool) and Model-2 (without tool), were developed in ANSYS Workbench 14.5. Cylindrical and Conical tool incorporated in Model-1 and remaining four tool geometries incorporated in Model-2 as a wall of tool impression. The shape and dimensions considered for the cylindrical and conical tools were similar as used in the experiment, and it was made of AISI H13 alloy steel. The model of the cylindrical and conical tool with the workpiece is shown in Figure 1. The shape and dimensions of the cylindrical and conical tool are shown in Figure 2. The manufactured tool of cylindrical and conical geometry for the experiments is shown in Figure 3.

\section{EXPERIMENTAL PROCEDURE}

For the present work, the experiment was conducted on a semi-automatic FSW machine having eighteen feed rate (20 $\mathrm{mm} / \mathrm{min}$ to $300 \mathrm{~mm} / \mathrm{min}$ ) and six spindle speeds. It is having $1600 \times 400 \mathrm{~mm}$ table size with a ' $\mathrm{T}$ ' slot with a centralized lubrication system. Two separate plates of aluminum alloy AA6061-T6 was cut according to dimension describe above from a large sheet and those surfaces which are butt together finished by milling process on a milling machine. This finishing is necessary to get proper and strong joint and better alignments at the weld centreline. A $100 \mathrm{~mm}$ round bar of AISI H13 alloy steel was taken and cut in two pieces through 'wire-EDM,' and these two pieces achieved the desired shape and dimensions, as shown in Figure 3 with the help of turning operation on lathe machine.

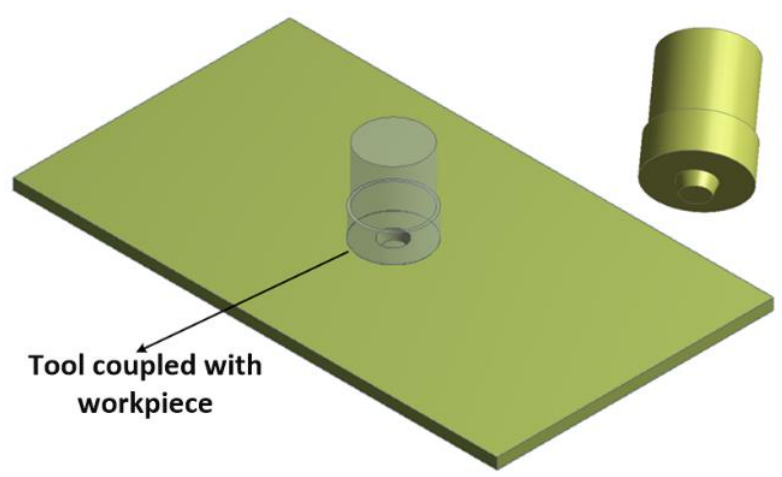

(a) Model - 1

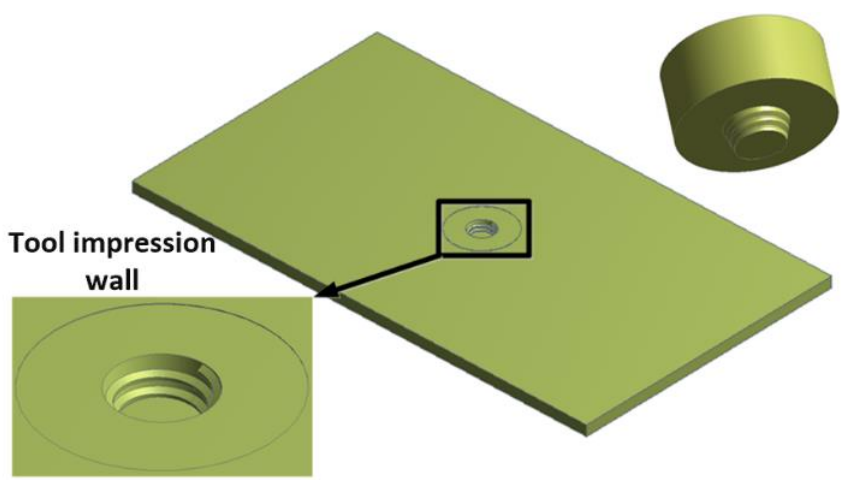

(b) Model - 2

Figure 1 Different models used for numerical analysis 


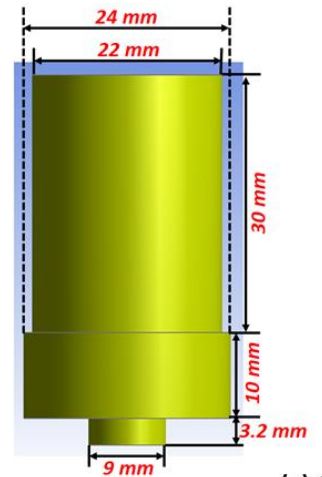

(a) Cylindrical

(b) Conical

(c) Conical threaded

(d) Tapered triflute

(e) Tapered triflat

(f) Tapered trivex

(a)
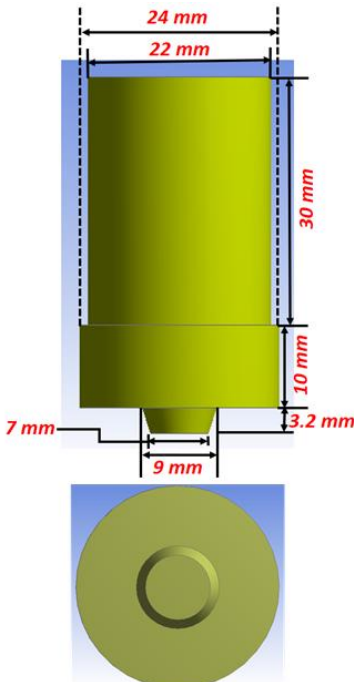

(b)

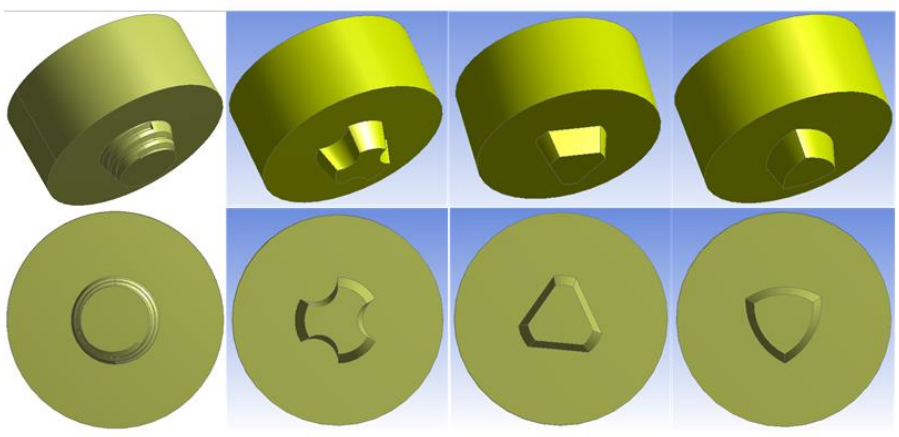

(c)

(d)

(e)

(f)

Figure 2 Tool incorporated in model-1 (a, b) and in model-2 (c, d, e, and f)

A proper bed, backing plate, and fixture was prepared according to the dimension of plates to hold the plates in a proper and fixed manner. Plunge-depth $(0.1 \mathrm{~mm}$ in present work) and center-line correction along with shoulder and tool pin respectively were done before welding. $180 \mathrm{~mm} / \mathrm{min}$ traverse speed and $1230 \mathrm{rpm}$ tool rotation was choosing for welding. When weld got started, the tool rotated for some time and contacting the plates. This small time period is known as 'dwelling period,' which made the material soft enough. After this small period, the tool had given the feed, i.e., traverse speed. Now tool rotates as well as translate in welding direction. Due to tool rotation, softer material ahead of the tool, near the weld line, flows radially outwards while pin gripped and guide the material under the shoulder which produced helical wave around the tool in the deformed region. This helical wave generated at the advancing side and ended towards the trailing side where weld got completed.

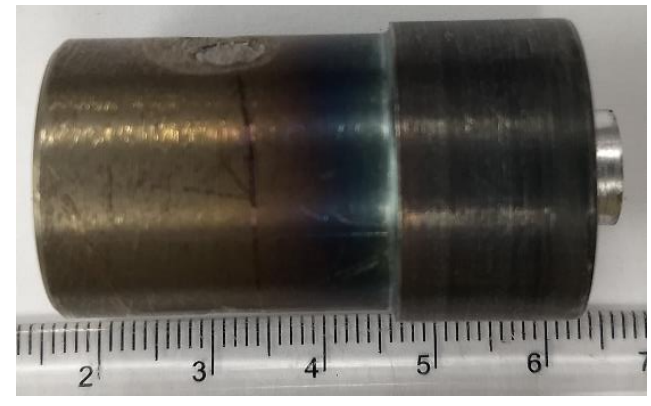

(a)

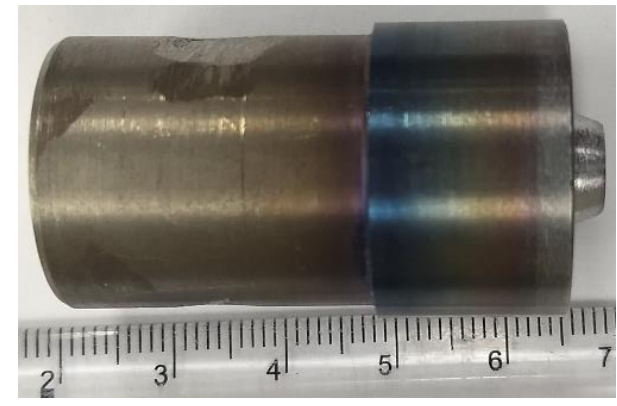

(b)

Figure 3 Tool used for experiments (a) cylindrical and (b) conical 
It mechanically intermixes the two pieces of workpiece material and forges the hot and softened material by mechanical pressure, which is applied by the shoulder to constrain the plasticized material around the pin. Due to traversed and rotation of shoulder and pin along the weld line, advancing side and a retreating side are formed, and the softened and heated material flows around the probe to its backside where the material is consolidated to create a high-quality solid-state weld. The schematic diagram of the FSW has been shown in Figure 4.

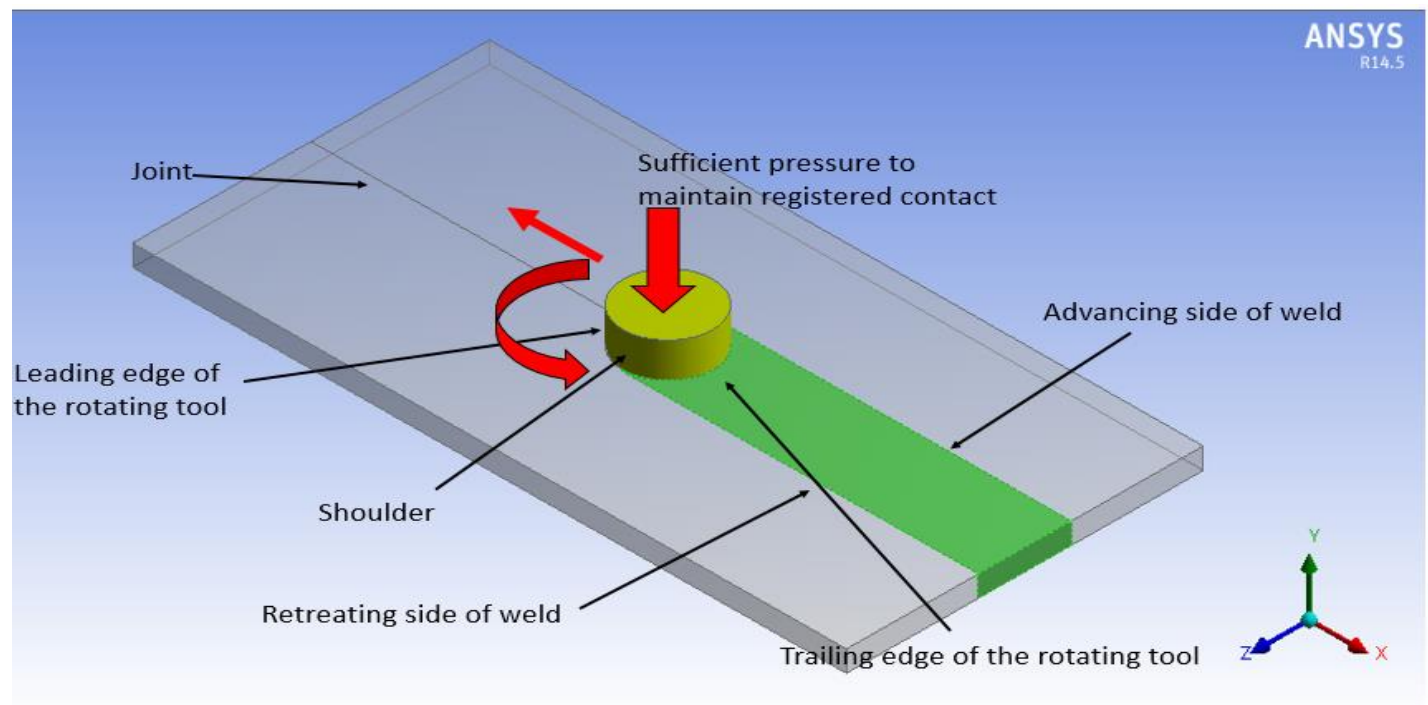

Figure 4 Schematic diagram of FSW

\section{MATERIAL PROPERTY}

All material properties for workpiece (AA6061-T6) and tool (AISI H13) are listed in Table 1.

Table 1 Materials property and their values or unit used in the study [13, 14]

\begin{tabular}{cc}
\hline Material property/ Process parameter & Value/Unit \\
\hline Workpiece material & AA6061-T6 \\
\hline Workpiece density; $\rho$ & $2700 \mathrm{~kg} / \mathrm{m}^{3}$ \\
\hline Thermal conductivity & $\mathrm{W} / \mathrm{m} / \mathrm{K}$ \\
\hline $\begin{array}{c}\text { Specific heat } \\
C_{p}=5 \times 10^{-7} T^{3}-7 \times 10^{-6} T^{3}-8 \times 10^{-3} T^{-3}+4.6745 T+90.792\end{array}$ & $\mathrm{~J} / \mathrm{kg} / \mathrm{K}$ \\
\hline Welding tool material & AISI H-13 \\
\hline Tool density; $\rho$ & $7800 \mathrm{~kg} / \mathrm{m}^{3}$ \\
\hline Thermal conductivity & $\mathrm{W} / \mathrm{m} / \mathrm{K}$ \\
\hline Specific heat; $C_{p}$ & $460 \mathrm{~J} / \mathrm{kg} / \mathrm{K}$ \\
\hline Weld speed & $180 \mathrm{~mm} / \mathrm{Min}^{2}$ \\
\hline Rotational speed & $875 \mathrm{and} 1230 \mathrm{rpm}$ \\
\hline Constant; $A$ & $1.26 \times 10^{8} \mathrm{sec}^{-1}$ \\
\hline Activation energy; $Q$ & $134.1584 \mathrm{kj} / \mathrm{mol}$ \\
\hline Universal gas constant; $\bar{R}$ & $8.314 \mathrm{kj} / \mathrm{kgmol} / \mathrm{K}$ \\
\hline 3
\end{tabular}




\begin{tabular}{cc}
\hline Power exponent; $n$ & 3.24644 \\
\hline Constant; $\alpha$ & $0.03055 \mathrm{Mpa}^{-1}$ \\
\hline Plunging pressure; $P$ & $11.2 \mathrm{Mpa}$ \\
\hline
\end{tabular}

The most important material property for the workpiece is its dynamic viscosity, which not be constant throughout the workpiece. Due to interaction between tool and workpiece at shoulder/work interface, the temperature is higher in this region hence low viscous material present near this region. Away from interface temperature gets reduced, and viscosity becomes high in this region, which shows the presence of a non-flow capable region. Colegrove et al. [6] approximated the viscosity of soft aluminum in terms of flow stress and effective strain rate, and it is given by equation (1).

$$
\eta=\frac{\sigma_{R}}{3 \dot{\varepsilon}}
$$

This expression of variable non-Newtonian viscosity has given as input to Fluent in the material property section with the help of a UDF. As simulation proceeds, the local value of temperature and strain rate adjust itself within Fluent according to the equation written below.

The effective strain rate $\dot{\varepsilon}$ can be expressed in terms of strain rate $\varepsilon_{i j}$ in equation (2).

$$
\dot{\varepsilon}=\left(\frac{2}{3} \varepsilon_{i j} \varepsilon_{i j}\right)^{\frac{1}{2}}
$$

Where, stain rate, $\varepsilon_{i j}$ is written in indicial notation in equation (3).

$$
\varepsilon_{i j}=\frac{1}{2}\left(\frac{\partial u_{i}}{\partial x_{j}}+\frac{\partial u_{j}}{\partial x_{i}}\right)
$$

$\sigma_{R}$ representing the flow stress which is given by Zener-Holloman and follow the relations given in equation (4).

$$
\sigma_{R}=\frac{1}{\alpha} \sinh ^{-1}\left(\frac{Z}{A}\right)
$$

In equation (4), $\mathrm{Z}$ is the Zener-Holloman parameter having the same unit as the strain rate unit, which can be expressed by equation (5).

$$
Z=\dot{\varepsilon} e^{\left(\frac{Q}{\bar{R} T}\right)}
$$

The function $\sinh ^{-1}\left(\frac{Z}{A}\right)$ is not defined in C-language, which creates a problem to write the code of viscosity; hence, the alternative expression $\sigma_{R}$ is written in equation (6). 


$$
\sigma_{R}=\frac{1}{\alpha}\left[\left(\frac{Z}{A}\right)^{\frac{1}{n}}+\left(1+\left(\frac{Z}{A}\right)^{\frac{2}{n}}\right)^{\frac{1}{2}}\right]
$$

\section{BOUNDARY CONDITIONS}

In the actual process of FSW, maximum material movement occurs around the tool shoulder; hence, the workpiece divided between the flow-capable region and non-flow capable region. Variable viscosity only has given to be in the flow-capable region having a width of $36 \mathrm{~mm}$, and the non-flow capable region has assigned with a dynamic viscosity having a magnitude of $10^{6} \mathrm{~Pa}-\mathrm{s}[14]$. This much higher viscosity almost cannot be able to flow.

AA6061-T6 has been considered as a fluid with variable viscosity and assigned for region-2, as evidently shown in Figure 5. Interface boundary, which divides the flow and non-flow region are moving with the tool traverse speed, i.e., $180 \mathrm{~mm} / \mathrm{min}$. Fluid entering from the inlet at the same traverse speed and interacts with the rotating tool (875 rpm and $1230 \mathrm{rpm}$ are taken for parametric study in Model-1) at the center of the workpiece. This relative motion between tool and fluid simulates the real process of FSW.

All external walls of the workpiece are stationary and given a heat transfer coefficient, $h=25 \mathrm{~W} / \mathrm{m}^{2} \mathrm{~K}$ but the value of the heat transfer coefficient at the bottom wall has taken $200 \mathrm{~W} / \mathrm{m}^{2} \mathrm{~K}$, considering it as a backing plate. Besides this tool rotation, two other boundaries conditions have been applied for the different tool geometries in Model-1. The first one is - the outer wall of the rotating tool in Model-1, assigned with a heat transfer coefficient, $h=10 \mathrm{~W} / \mathrm{m}^{2} \mathrm{~K}$ but in Model-2 which consisting only tool impression wall instead of incorporating actual tool has not been assigned to any heat transfer coefficient because of absence of tool as a heat transfer medium normal to tool depression wall. Second boundary conditions are common for both Model-1 and Model-2 which contain heat flux value at tool/workpiece interface for Model-1 and same for Model-2 at rotating tool impression wall with an understanding of distribution of heat between tool and workpiece because tool has been not considered for Model-2.

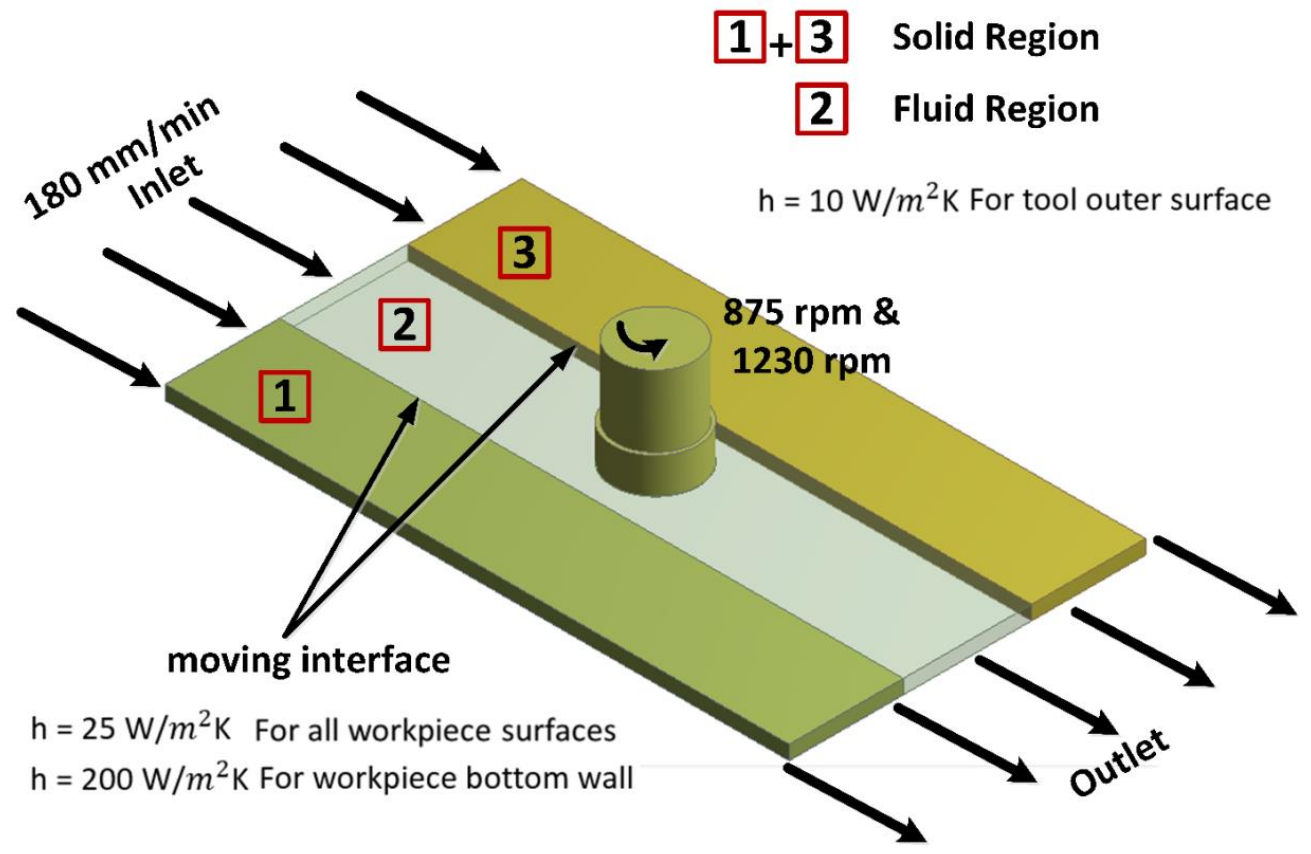


Figure 5 Boundary conditions used in the study

In this work, no-slip boundary condition has applied at the interface, but different conditions have been considered for calculating heat. Basically, around the tool, material flow is partially slipping and partially sticking. Hence, a factor defined known as SLIP FACTOR denoted by ' $\delta$ ' for the combined effect and the expression of heat generation is given by the equation (7).

$$
Q_{\text {total }}=(1-\delta) Q_{\text {sliding }}+\delta Q_{\text {sticking }}
$$

Here $Q_{\text {sliding }}$ is heat generated due to the frictional effect and $Q_{\text {sticking }}$ is heat generation between shear layers. When $\delta=0$, heat is produced only by friction. When $\delta=1$, heat generated solely governed by plastic deformation. In present work, $\delta=0.35$ [15] has taken for shoulder surface and probe tip surface because the sliding condition is more dominant in this region. For probe side surface $\delta=0.5$ [15] has taken the reason for considering this value is that material around the probe side softened significantly by the friction heat.

Equations (8) and (9) represent the heat generation equation for conical tool geometry [Figure 2 (b) and remaining four tool pin profile desiged within a same frustrum having bigger diameter of $9 \mathrm{~mm}$ and smaller diameter of 7 $\mathrm{mm}$. In the FSW process, the heat is generated mainly near the workpiece-tool interface area which may have complex geometris based on their tool pin profile shape. However, in this work, Equation (8) and (9) also be used for conical threaded, tapered triflute, tapered triflat and tapered trivex tool geometries (Figure 2) because of if we consider the case of tapered triflute geometry, it contains six lateral surfaces in which three are concave and three are convex surfaces and area of each six surfaces are same. Hence, pin side surface area for tapered triflute tool is same as of conical tool, also due to complex curvature in this tool we can see that increaded in sholder surface area is eual to decrease in pin bottom surface area. Similar comparision analysed for other three tapered tool and it is assumed that Equation (8) and (9) can be used for all these four tapered tool considering that insignificant variation observed in total heat generation [17] but heat flux at interface is different [18] for each tool because their shoulder surface area, pin bottom surface area and pin side surface area are diffesent as listed in $\underline{\text { Table } 3}$ and these different heat flux value has been given at the interface in this model.

$$
\begin{gathered}
Q_{\text {sliding }}=\frac{2}{3} \pi \mu \omega P\left(R^{3}-r_{b}^{3}\right)+\frac{2}{3} \pi \mu \omega P r_{t}^{3}+\frac{2}{3 \sin \theta} \pi \mu \omega P\left(r_{b}^{3}-r_{t}^{3}\right) \\
Q_{\text {sticking }}=\frac{2}{3} \pi \omega \tau\left(R^{3}-r_{b}^{3}\right)+\frac{2}{3} \pi \omega \tau r_{t}^{3}+\frac{2}{3 \tan \theta} \pi \omega \tau\left(r_{b}^{3}-r_{t}^{3}\right)
\end{gathered}
$$

The heat equation for cylindrical tool geometry is given by equations (10) and (11), and these equations also divided by surface area of the different tool faces of cylindrical tool to get the heat flux.

$$
\begin{gathered}
Q_{\text {sliding }}=\frac{2}{3} \pi \mu \omega P\left(R^{3}-r_{b}^{3}\right)+\frac{2}{3} \pi \mu \omega P r_{t}^{3}+2 \pi \mu \omega P R^{2} l \\
Q_{\text {sticking }}=\frac{2}{3} \pi \omega \tau\left(R^{3}-r_{b}^{3}\right)+\frac{2}{3} \pi \omega \tau r_{t}^{3}+2 \pi \omega \tau R^{2} l
\end{gathered}
$$


For Model-1, i.e., the model which incorporates conical and cylindrical tools along with workpiece, heat flux is given at tool/workpiece interface, and this heat flux is shared among workpieces and tools via system coupling. This coupling, represented by equation (12) [16].

$$
K \frac{\partial T}{\partial N}=\frac{\sqrt{\left(K \rho C_{p}\right)_{\text {workpiece }}}}{\sqrt{\left(K \rho C_{p}\right)_{\text {tool }}}+\sqrt{\left(K \rho C_{p}\right)_{\text {workpiece }}}}
$$

Where, $K, \rho$ and $C_{p}$ represents the thermal conductivity, density, and specific heat for tool and workpiece. Here, $N$ represents the normal vector at the tool/the work interface.

But for Model-2, i.e., the model incorporated with only tool impression wall Figure 6 (b), calculated heat flux multiplied with a factor $\beta$ according to equation (13) [16] and then given to tool impression wall. This is done because of non-availability of actual tool in which some portion of generated heat must be transferred.

$$
\beta=\frac{\sqrt{\left(K \rho C_{p}\right)_{\text {workpiece }}}}{\sqrt{\left(K \rho C_{p}\right)_{\text {tool }}}+\sqrt{\left(K \rho C_{p}\right)_{\text {workpiece }}}}
$$

The moving interface, which separates different regions of the workpiece, transfer the heat via system coupling.

\section{GOVERNING EQUATIONS}

This FVM model simulation has conducted for highly viscous material, which may plasticize due to rotation of tool and heat produced by solid-fluid interaction. For simplification of the model, the following assumption can be made:

- Laminar flow in steady state.

- No tilt angle is given to the spindle of the tool.

- No heat generation is considered inside the material.

- 'No-slip' condition was used at the contact between the tool wall and fluid.

- Incompressible fluid i.e., constant density.

- Heat loss from radiation is negligible.

- The effect of gravity on flow is negligible.

Applying the above assumptions, few sets of equations solved by Fluent which are written as continuity equation:

$$
\rho\left(\frac{\partial u}{\partial x}+\frac{\partial v}{\partial y}+\frac{\partial w}{\partial z}\right)=0
$$

$\mathrm{x}$-momentum equation: 


$$
\rho u \frac{\partial u}{\partial x}+\rho v \frac{\partial u}{\partial y}+\rho w \frac{\partial w}{\partial z}=F_{x}-\frac{\partial p}{\partial x}+\eta\left(\frac{\partial^{2} u}{\partial x^{2}}+\frac{\partial^{2} u}{\partial y^{2}}+\frac{\partial^{2} u}{\partial w^{2}}\right)
$$

y-momentum equation:

$$
\rho u \frac{\partial v}{\partial x}+\rho v \frac{\partial v}{\partial y}+\rho w \frac{\partial v}{\partial z}=F_{y}-\frac{\partial p}{\partial y}+\eta\left(\frac{\partial^{2} v}{\partial x^{2}}+\frac{\partial^{2} v}{\partial y^{2}}+\frac{\partial^{2} v}{\partial w^{2}}\right)
$$

z-momentum equation:

$$
\rho u \frac{\partial w}{\partial x}+\rho v \frac{\partial w}{\partial y}+\rho w \frac{\partial w}{\partial z}=F_{z}-\frac{\partial p}{\partial z}+\eta\left(\frac{\partial^{2} w}{\partial x^{2}}+\frac{\partial^{2} w}{\partial y^{2}}+\frac{\partial^{2} w}{\partial w^{2}}\right)
$$

Energy equation:

$$
\rho C_{p} \frac{\partial T}{\partial x}+\rho C_{p} \frac{\partial T}{\partial y}+\rho C_{p} \frac{\partial T}{\partial z}=K\left(\frac{\partial^{2} T}{\partial x^{2}}+\frac{\partial^{2} T}{\partial y^{2}}+\frac{\partial^{2} T}{\partial w^{2}}\right)
$$

\section{SOLVER AND DISCRETIZATION SCHEME}

The governing partial differential equations being solved using the commercial software ANSYS Fluent 14.5. In the software, the Finite Volume Method (FVM) is used for solving the governing equations. The mesh adopted for the model is shown in Figure 6. The governing equations are discretized on individual control volume to get a system of linear algebraic discretized equations. The system of linear equations is solved by the iterative methods.

Pressure based solver is used in this numerical work because density is constant for weldment. The second-order upwind scheme is used in the discretization of convection-diffusion terms. The pressure velocity coupling is solved using the Semi-Implicit Method for Pressure Linked Equations (SIMPLE) algorithm. In the iteration process of solving a system of linear equations, the solution domain was started with zero velocities and temperature, which were equal to the ambient temperature throughout the domain.

The iterations are continued till the magnitude of the residues of the equations in all the control volumes is brought down to less than a small numerical value $\delta . \delta$ used for continuity equation: $10^{-6}$, x, y and $\mathrm{z}$ momentum equations: $10^{-6}$ and energy equation: $10^{-6}$. Under relaxation is used for pressure, density, body force, momentum, and energy to handle the nonlinearities of the equations. The values of under relaxation factors used are dependent on the complexity of the problem. Typical values used for $p, F, \rho, u, v, w$ and $T$ are 0.3, 1, 1, 0.6, 0.6, 0.6 and 0.7. Double precision is used throughout the computations. The simulation has performed on a computer using a 5core processor, a clock speed of $2.60 \mathrm{GHz}$ and $8 \mathrm{~GB}$ of RAM.

\section{MESH STUDY}

It was known that the region in which tool travels along the weld length was the region of concern. Except for this region, all regions remain as solid in the FSW process. Hence only the tool shoulder travel area (region 2) needs to be focused. Hence, the mesh has made coarse in regions 1 and 3 and fine in region 2, as evident from Figure 6. 
Before the discussion of a result, it has to be necessary to check the quality of mesh developed for simulation. In this study, four types of mesh were generated with decreasing order of element size (discussed in Table 2), and the effect of meshing on the solution was observed with the help of temperature contour, as evident from Figure 7.

A significant difference in the cooling curve profile has observed for the first three grids with increasing computation time. But insignificant differences in temperature profile for grid 3 and 4 were observed, i.e., after grid 4, further reduction in element size did not vary the result but only increased the computation time. Hence, meshing with grid 3-type was considered for further process considering the fact that it almost gives similar results as of grid 4 with a significant saving of computation time.

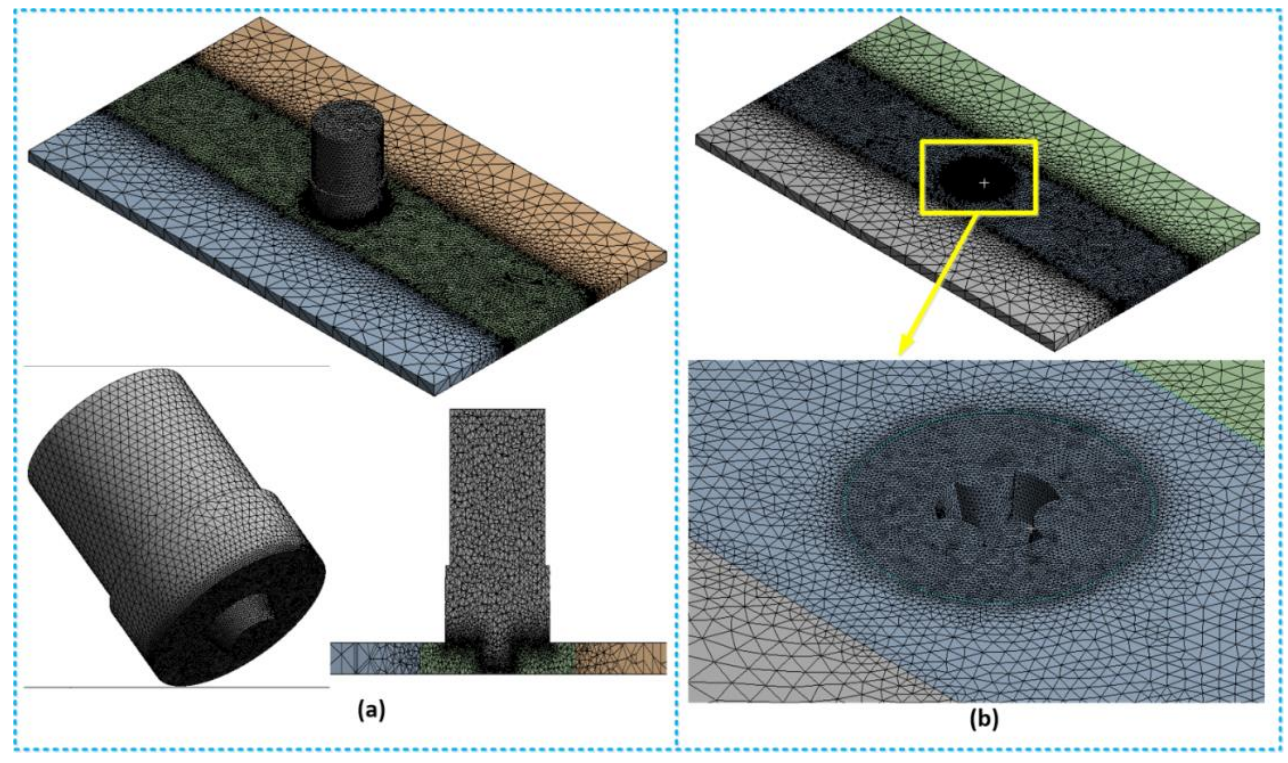

Figure 6 Mesh used in the study (a) Model-1 with a tool (b) Model-2 without tool

Table 2 Simulation time for different elements

\begin{tabular}{ccc}
\hline Name & Number of elements & Simulation time \\
\hline Grid 1 & 195925 & $4 h: 45 m: 3 s$ \\
\hline Grid 2 & 338046 & $5 h: 56 m: 31 s$ \\
\hline Grid 3 & 392414 & $7 h: 34 m: 6 s$ \\
\hline Grid 4 & 486522 & $8 h: 48 m: 37 s$
\end{tabular}

This mesh analysis performed for conical tool geometry with the tool. Further generation of mesh for another type of tool geometry with or without a tool, the idea of minimum element size has taken. The minimum element size taken in this study was $0.3 \mathrm{~mm}$.

\section{RESULTS AND DISCUSSION}

\subsection{Temperature distribution}

The different fully-coupled models were used in the present study incorporating six tool geometries. The thermal analysis cleared the picture of temperature distribution in the workpiece and the heat transfer between tool and workpiece while the material flow analysis gives the critical knowledge and snap-shot of material movement 
inside the plates around the tool under tool shoulder. The effect of tool rotational speed on temperature distribution was studied for cylindrical and conical tool geometry, and for better comparison, flow analysis was done at the same process parameters. The welding was achieved with the help of different tools having anticlockwise rotation and traveling along the weld center-line, which is taken in X-direction. Two sides that are the advancing side (AS) and retreating side (RS) were formed on negative and positive Z-direction, respectively, which completely depends upon the direction of tool travel and tool rotation. The longitudinal Y- axis considered as a rotation axis of tool coinciding with the origin at tool probe tip along the width of the plate. The planes and origin considered in the study are shown in Figure 8.

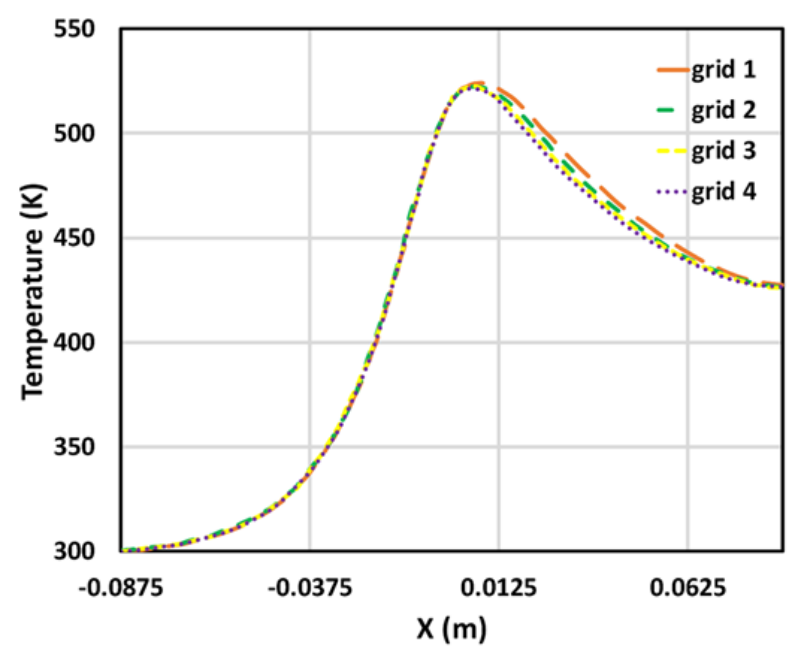

Figure 7 Comparison of different meshes of conical tool geometry by observing temperature profile for Model-1 on the advancing side (17 $\mathrm{mm}$ from weld centreline on the top surface)

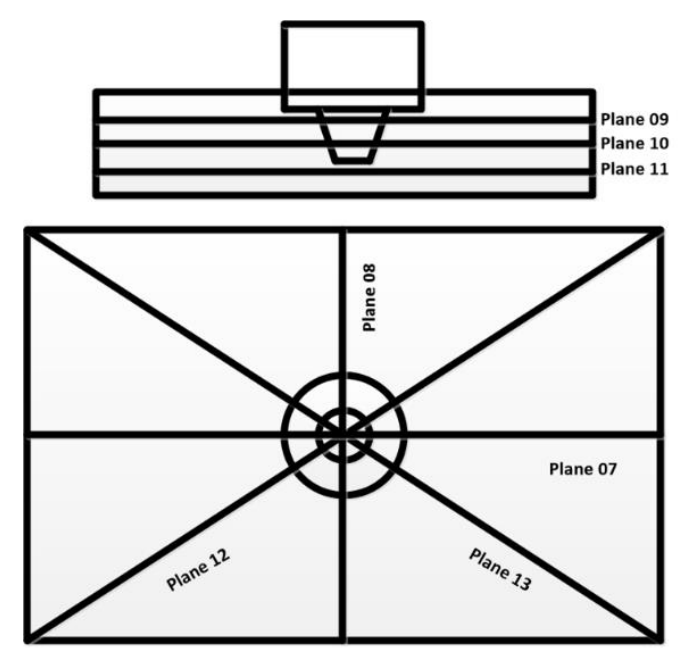

(a) Planes considered in this study

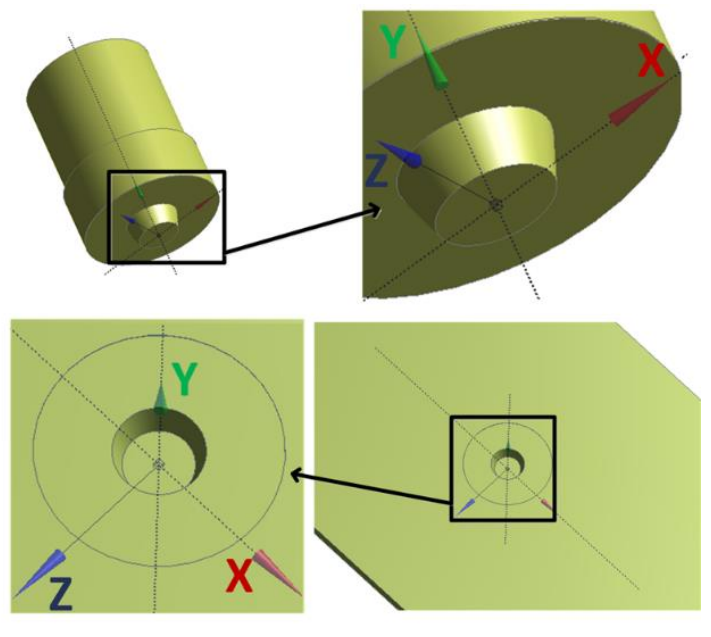

(b) Origin considered in this model

Figure 8 Planes and origin considered in the study

The temperature contours for cylindrical geometry obtained during FSW of AA6061-T6 at 875 rpm, 1230 rpm, and $180 \mathrm{~mm} / \mathrm{min}$ travel speed has shown in Figure 9. This represents only that part of the workpiece, which was considered as a flow capable region, i.e., a $36 \mathrm{~mm}$ width of the workpiece has shown instead of $100 \mathrm{~mm}$. In both cases, maximum temperature has observed at the shoulder interface in the advancing-trailing side closer to the advancing side of the welds. A maximum temperature (under the shoulder) of (645 K) $372{ }^{\circ} \mathrm{C}$ with wide contours was observed for $875 \mathrm{rpm}$, as evident from Figure 9. Weld with higher rotational speed (1230 rpm) show a higher 
temperature of $(764 \mathrm{~K}) 491{ }^{\circ} \mathrm{C}$ because of the higher frictional heat generation, but they have narrow contours and high temperatures towards the probe sides and probe end.
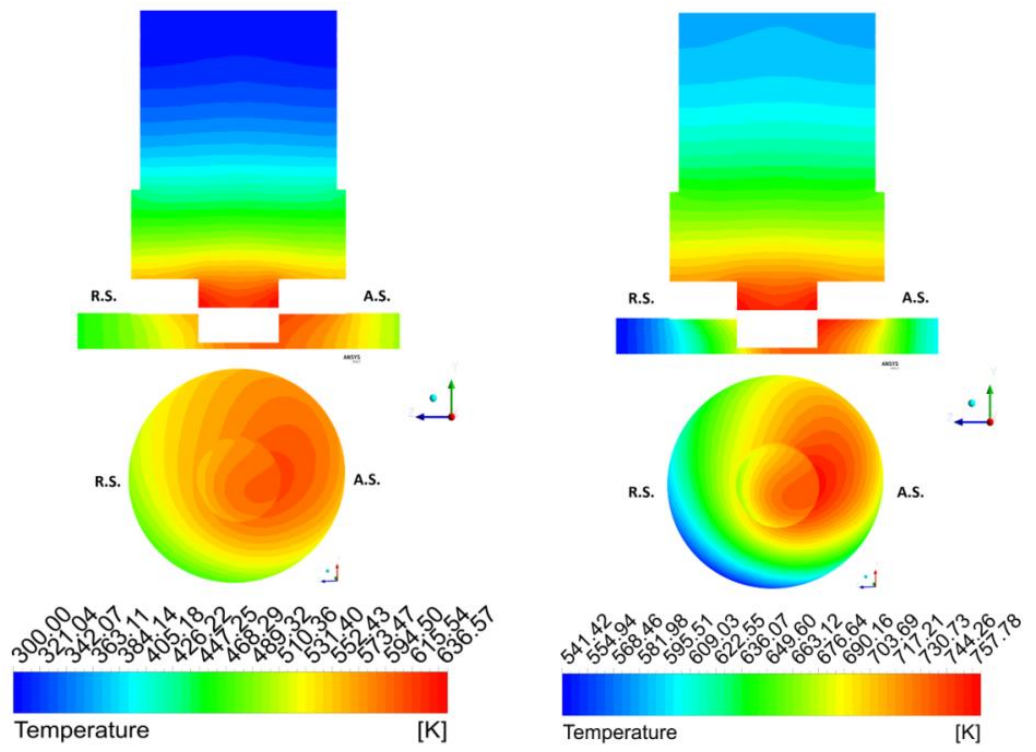

Figure 9 Temperature $(\mathrm{K})$ distribution in tool and workpiece along the cross-section of plane 8 and temperature contours in tool inside the shoulder at different rpm for cylindrical tool geometry

Temperature distribution in weldment has shown in Figure 10. Temperature decreased away from the mixing zone. It was found that the temperature distribution is asymmetric, which is an important characteristic of the FSW process, as evident from Figure 10. The flow of heat observed more on the advancing side, as evident from Figure 9 and Figure 10. This was attributed to the high relative velocity at the advancing side, causing more visco-plastic material shearing and, consequently, the higher heat generation through plastic deformation and viscous heating.

Figure 11 represents the shoulder/plate interface and temperature distribution between tool and workpiece at different welding conditions for conical tool geometry. A similar phenomenon was observed for the conical tool, as in the case of cylindrical tool geometry. It also shows a maximum temperature (under the shoulder) of (632 K) $359{ }^{\circ} \mathrm{C}$ with wide contours at $875 \mathrm{rpm}$. Weld with higher welding speed $(1230 \mathrm{rpm})$ shows a higher temperature of $(750 \mathrm{~K}) 477^{\circ} \mathrm{C}$. Figure 12 shows the temperature distribution in the workpiece for conical tool geometry.
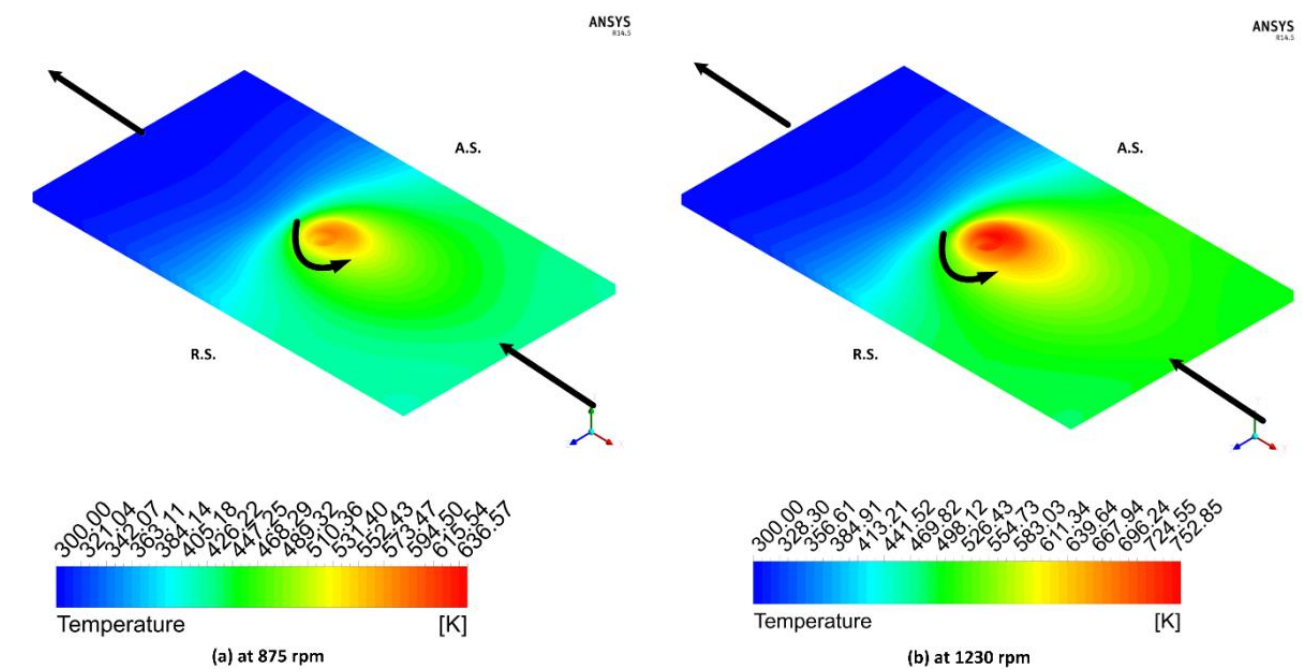
Figure 10 Temperature $(\mathrm{K})$ distributions in the workpiece at different rpm for cylindrical tool geometry

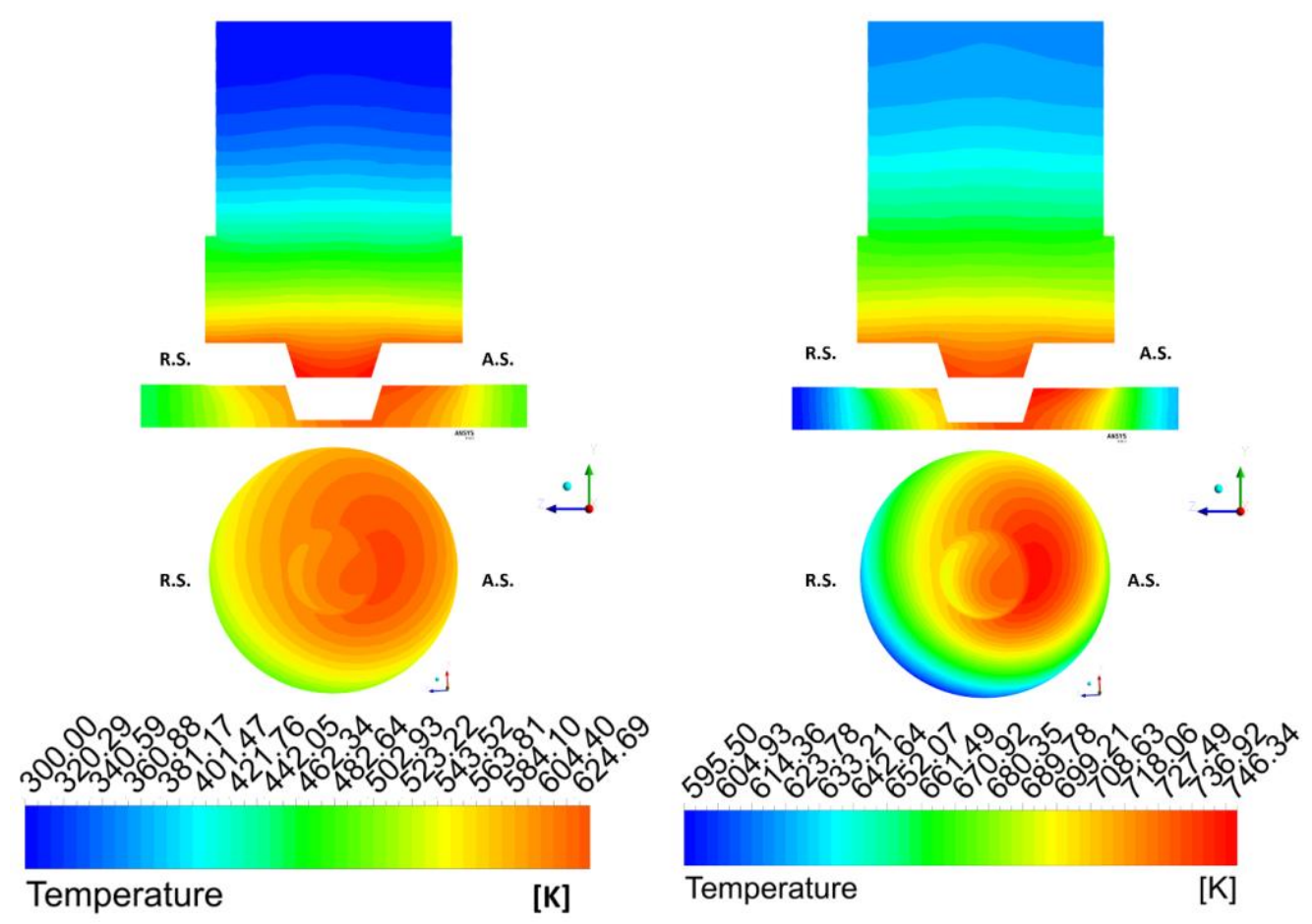

Figure 11 Temperature (K) distribution in tool and workpiece along the cross-section of plane- 8 and temperature contours in tool inside the shoulder at different rpm for conical tool geometry

ANSYS
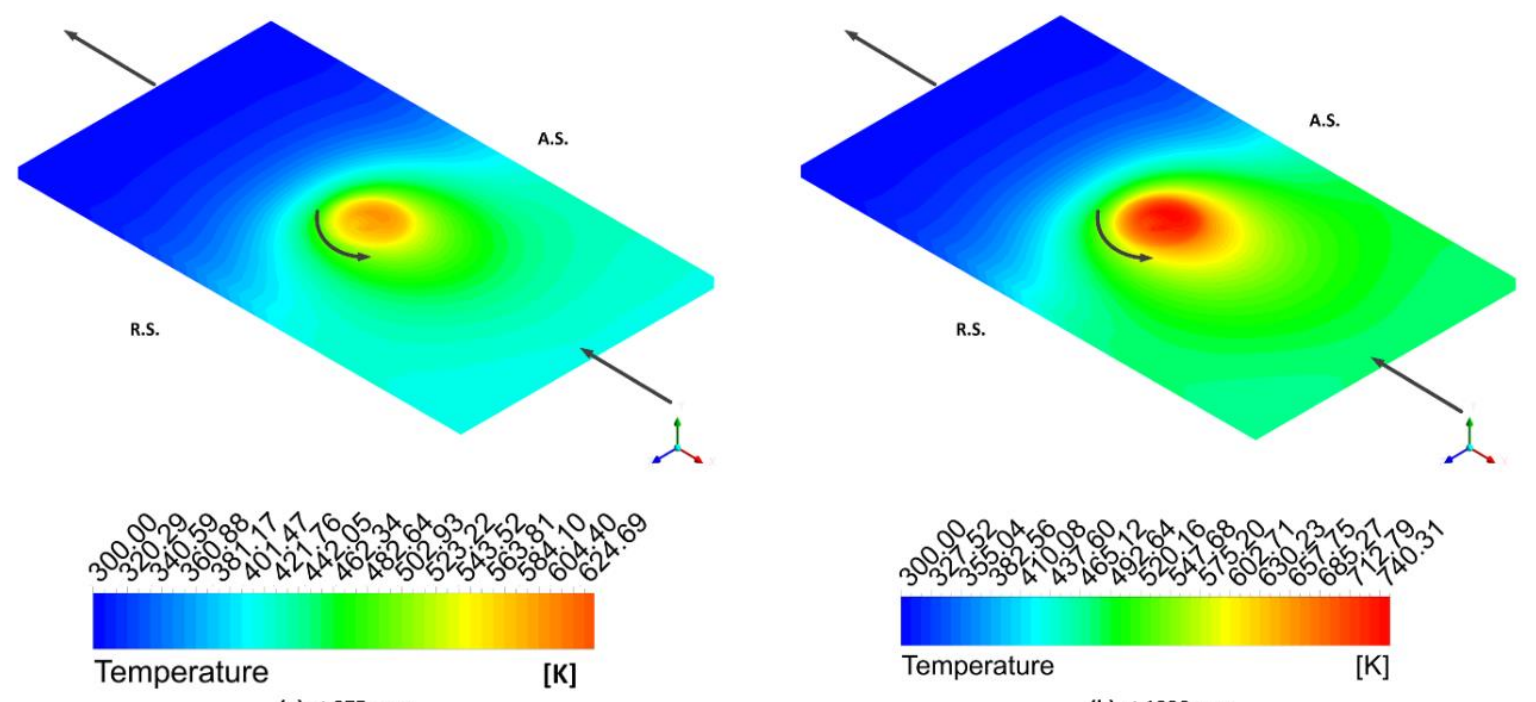

(a) at $875 \mathrm{rpm}$

(b) at $1230 \mathrm{rpm}$

Figure 12 Temperature (K) distributions in the workpiece at different rpm for conical tool geometries

Figure 13 represents the transient temperature distribution of model-1 for conical tool geometry. It shows that temperature increases as the welding progressed with time. It was observed that the distribution of temperature is more in the workpiece than the tool due to their different thermal conductivity; hence, heat transfer is different in tool and workpiece. 


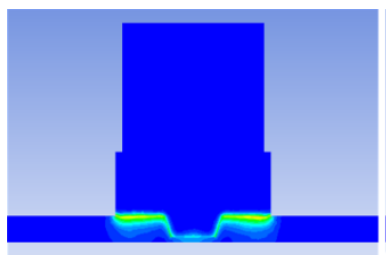

(a) $341 \mathrm{~K}$

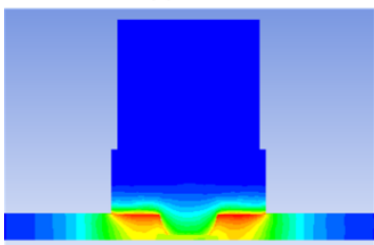

(e) $438 \mathrm{~K}$

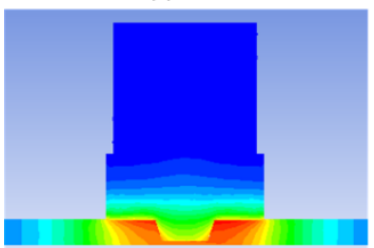

(i) $489 \mathrm{~K}$

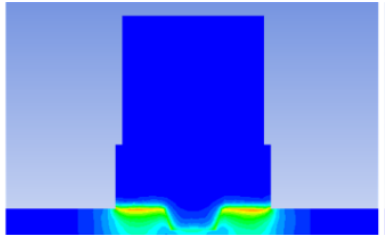

(b) $360 \mathrm{~K}$

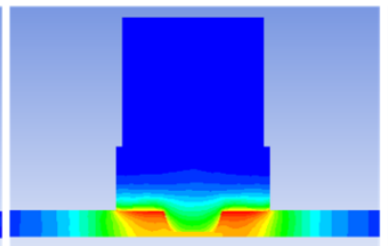

(f) $455 \mathrm{~K}$

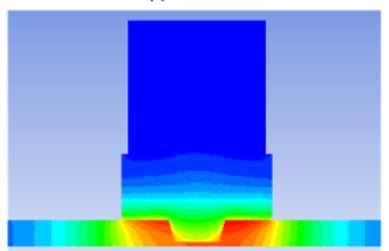

(j) $500 \mathrm{~K}$

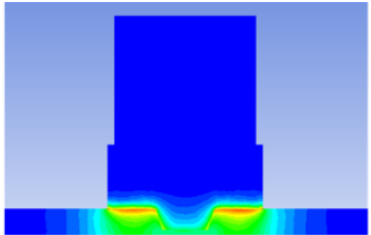

(c) $385 \mathrm{~K}$

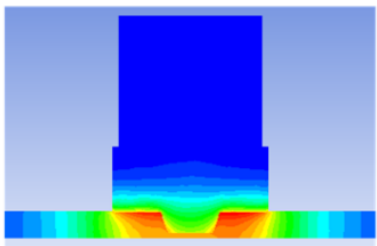

(g) $467 \mathrm{~K}$

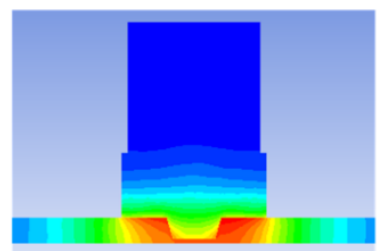

(k) $512 \mathrm{~K}$

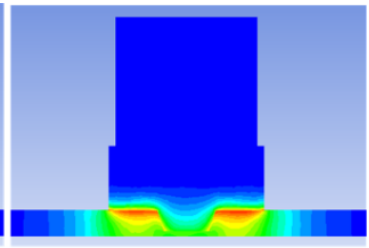

(d) $415 \mathrm{~K}$

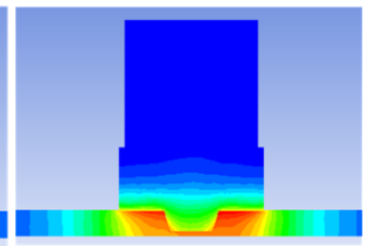

(h) $473 \mathrm{~K}$

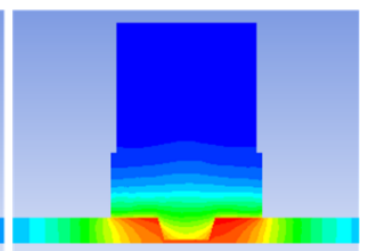

(I) $533 \mathrm{~K}$

Figure 13 Heat generation at shoulder/work interface as different instant

Temperature decreased along the width of the plate on both sides from the weld centreline as different region appears mechanically due to tool-work interaction. Stir zone has higher temperatures. Subsequently, thermomechanical affected zone (TMAZ), heat affected zone (HAZ), and parent material (PM) have a lower temperature zone, as shown in Figure 14.

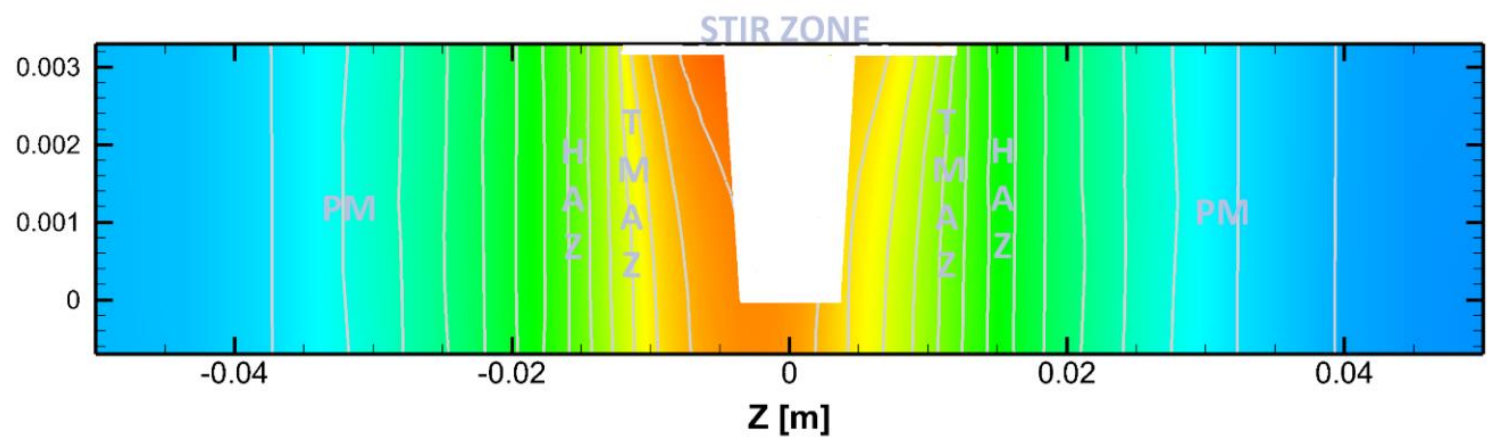

Temperature [K]

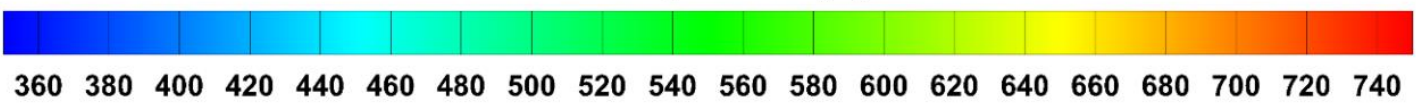

Figure 14 Temperature $(\mathrm{K})$ contour showing different region along the width of the workpiece

Figure 15 represents the distribution of temperature at different lines, situated both sides from the weld centreline at a distance of $17 \mathrm{~mm}, 22 \mathrm{~mm}$, and $30 \mathrm{~mm}$ on the top surface for cylindrical and conical tool geometry, respectively. These lines were tracking the path of the tool during the welding process. As the tool started to run for welding along the joint line, that time plate at room temperature. During dwelling period temperature rise to that extent, which made material capable of flowing after that temperature rises gradually up to half of the welding length as a tool is moving forward, which has shown by the rising curve. Subsequently, due to the higher thermal conductivity of aluminum, the joined part of the workpiece cooled down slowly, shown by the cooling curve. 

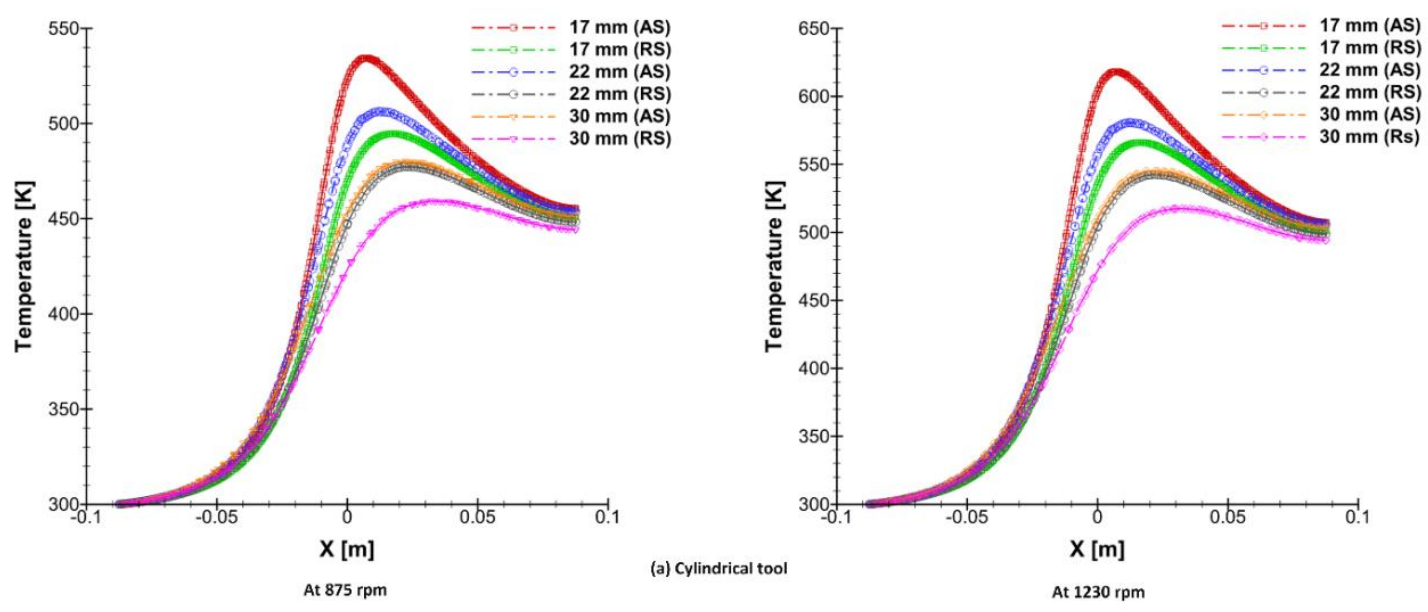

(a)
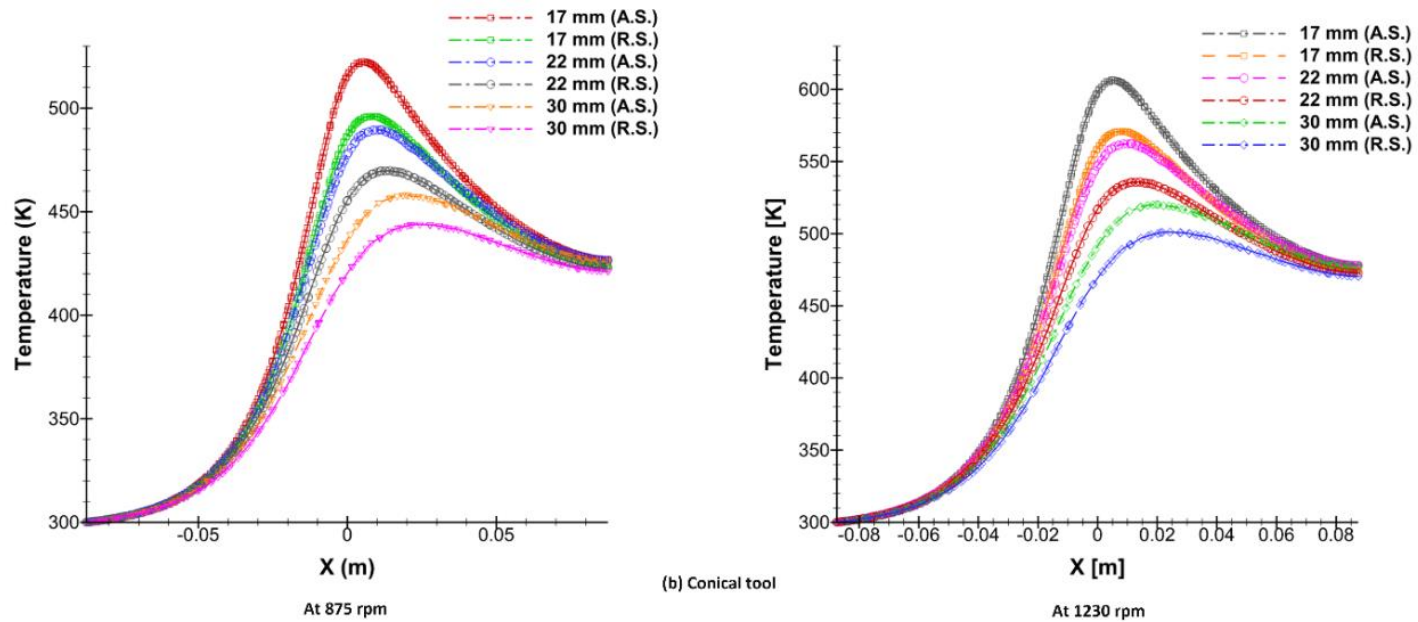

(b)

Figure 15 Difference in temperature profile for A.S. and R.S. in welding direction at different rpm for (a) cylindrical tool geometry and (b) conical tool geometry

Temperature contours in the workpiece for all four cases of Model-2 with their peak temperature has shown in Figure 16. The peak temperature is different in all cases shows that pin profile affects the heat generation due to different values of heat flux at the tool/work interface because of the change in their surface area. Peak temperatures with a different pin having different interface areas are shown in Table 3. 


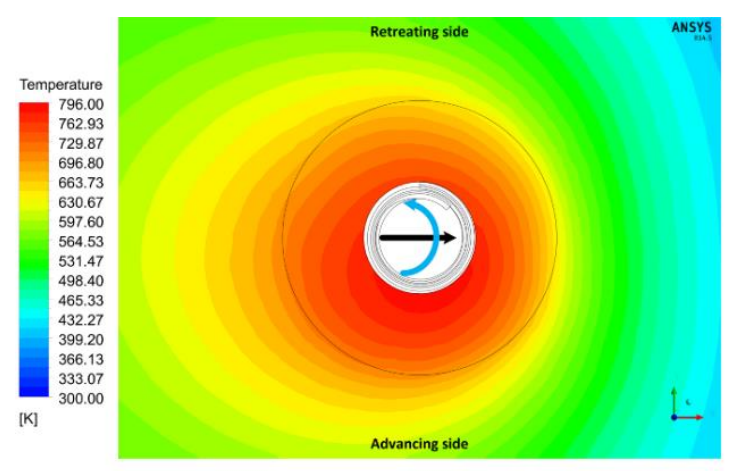

(a) Conical threaded

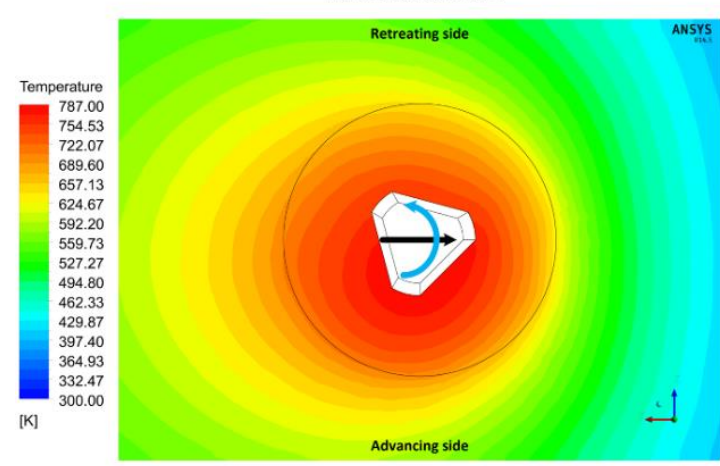

(c) Tapered triflat

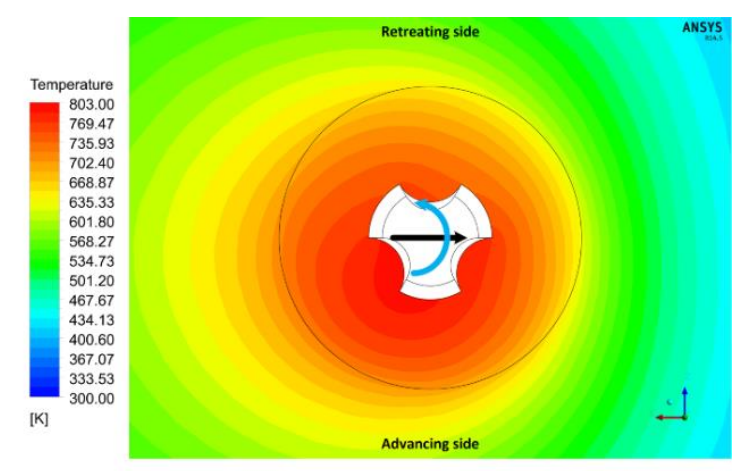

(b) Tapered triflute

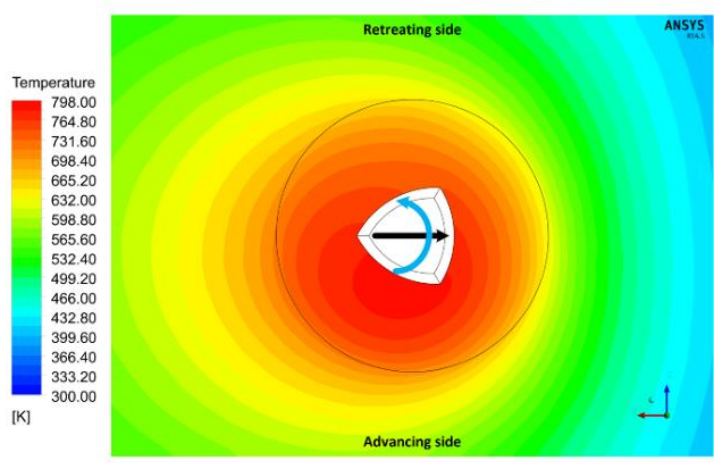

(d) Tapered trivex

Figure 16 Temperature distributions in workpiece for all four cases of Model-2

Table 3 Tool geometries with their interface area and peak temperature

\begin{tabular}{ccccc}
\hline Tool Geometry & $\begin{array}{c}\text { Shoulder Surface } \\
\text { Area }\left(\mathbf{m m}^{2}\right)\end{array}$ & $\begin{array}{c}\text { Pin Bottom } \\
\text { Surface Area } \\
\left(\mathbf{m m}^{2}\right)\end{array}$ & $\begin{array}{c}\text { Pin Side Surface } \\
\text { Area }\left(\mathbf{m m}^{2}\right)\end{array}$ & $\begin{array}{c}\text { Peak } \\
\text { Temperature (K) } \\
(\mathbf{a t} \mathbf{1 2 3 0} \mathbf{~ r p m})\end{array}$ \\
\hline Cylindrical & 388.772 & 63.617 & 90.478 & 764 \\
\hline Conical & 388.772 & 38.485 & 84.260 & 750 \\
\hline Conical Threaded & 388.772 & 36.988 & 104.012 & 796 \\
\hline Tapered Triflute & 406.712 & 27.631 & 88.947 & 803 \\
\hline Tapered Triflat & 406.102 & 27.996 & 76.682 & 787 \\
\hline Tapered Trivex & 408.252 & 26.695 & 72.285 & 798 \\
\hline
\end{tabular}

\subsection{Velocity distribution}

Plane near the shoulder shows a higher velocity due to the higher deformation zone, which influenced by the shoulder. For all tool geometries, similar flow patterns observed near the shoulder, which has a higher deformation zone in Figure 17. This shows that material flow mainly governed by the shoulder in a higher deformation zone. 


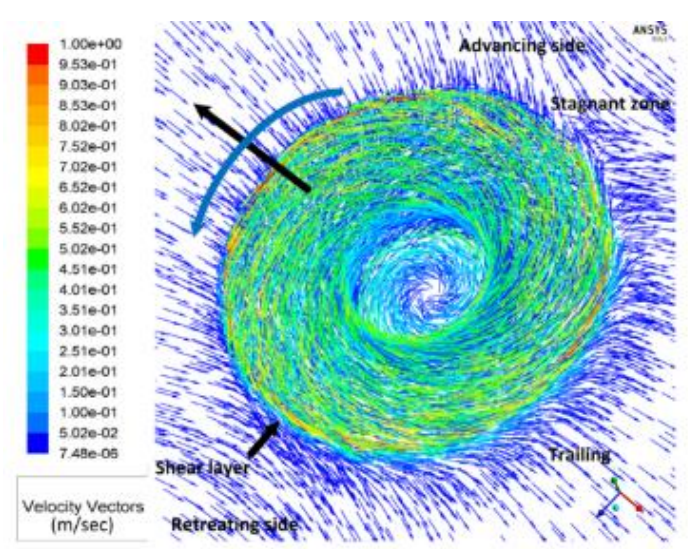

(a) Cylindrical

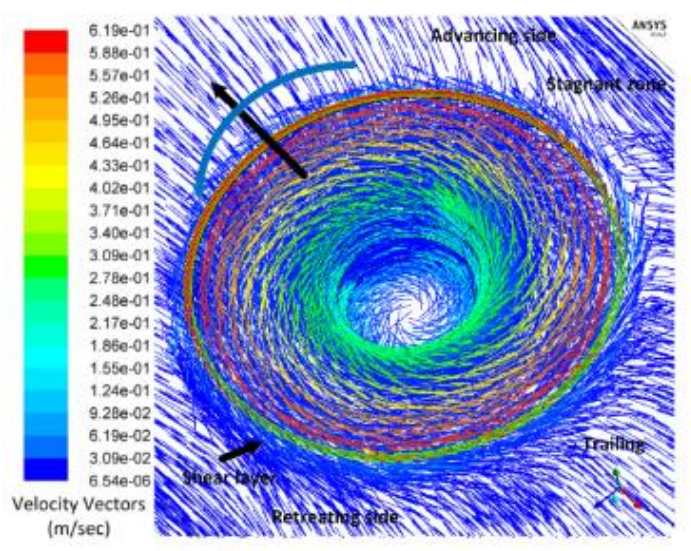

(c) Conical threaded

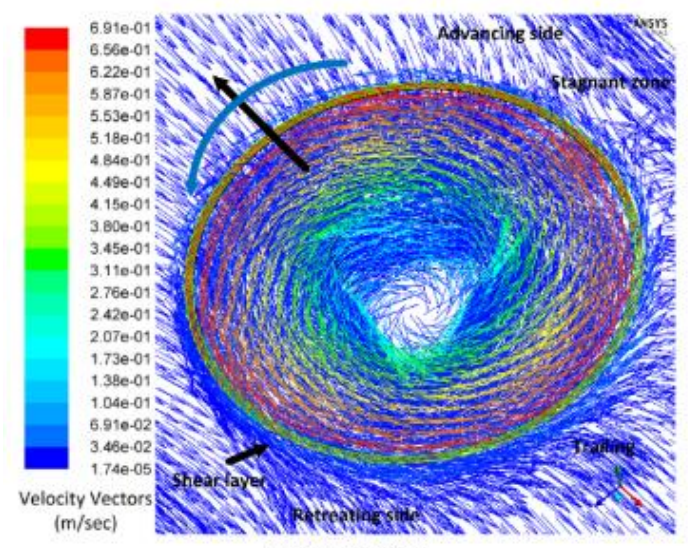

(e) Tapered triflat

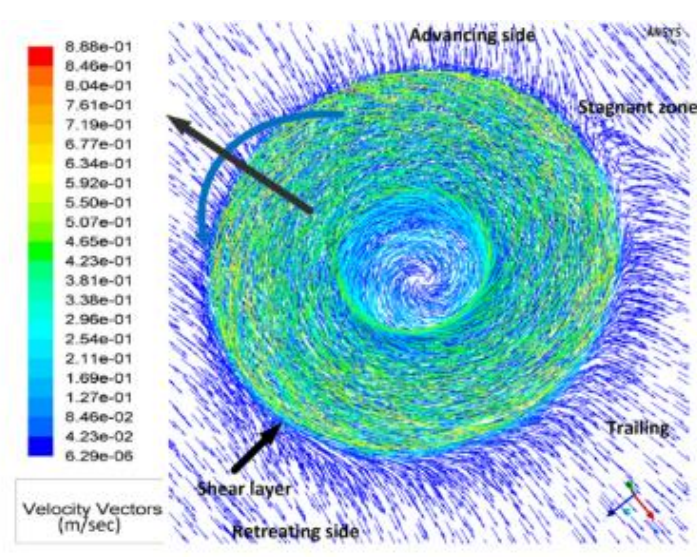

(b) Conical

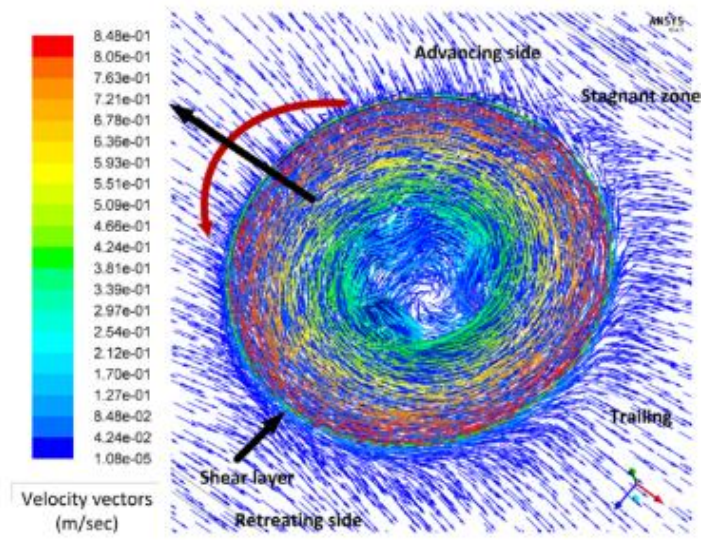

(d) Tapered triflute
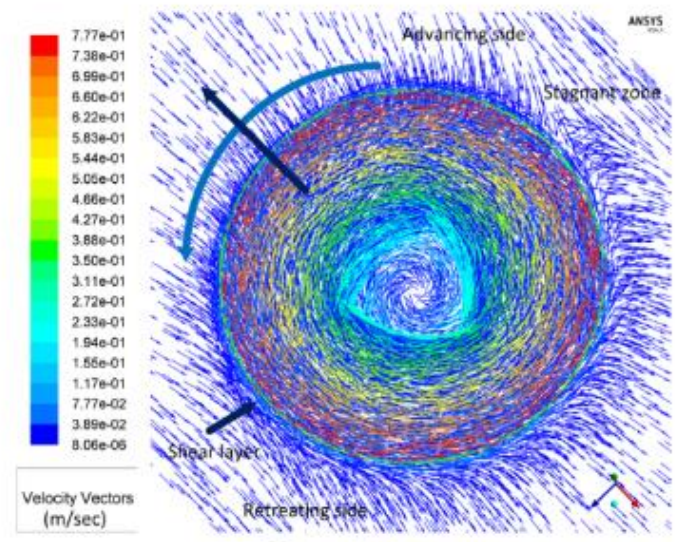

(f) Tapered trivex

Figure 17 Inclined view of the velocity vector in workpiece for all tool geometries

It was seen that identical flow patterns obtained in the first three cases, i.e., in Figure 18 (a, b, and c), but swirl is more uniform and concentrated in threaded pin than a conical and cylindrical pin. Flow has complex around the pin in case of triflute pin, as evident from Figure 18 (d). Some flow separation occurred in the concave grooved region; hence, this region has a lower velocity zone. 


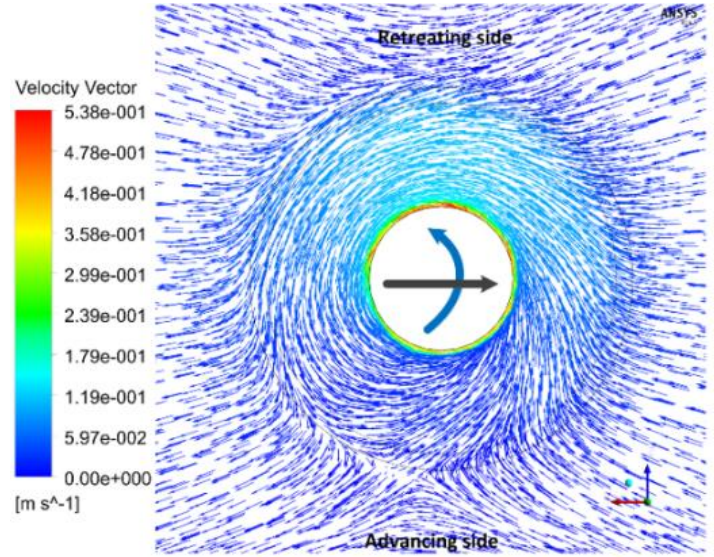

(a) Cylindrical

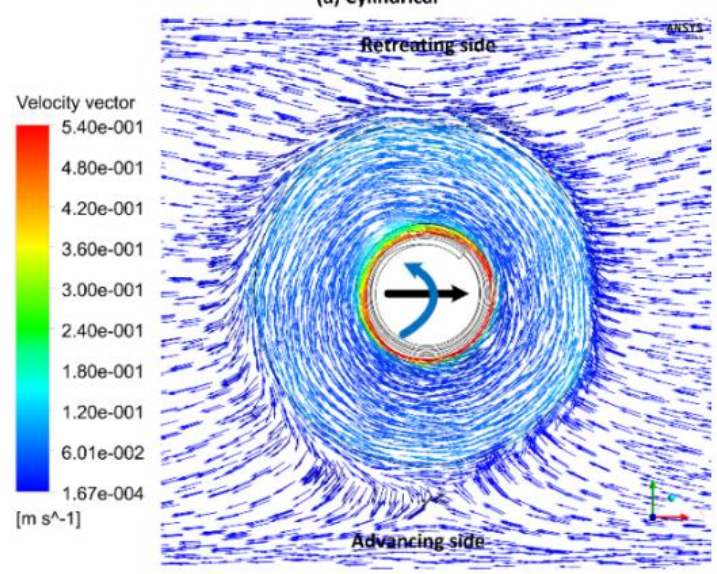

(c) Conical threaded

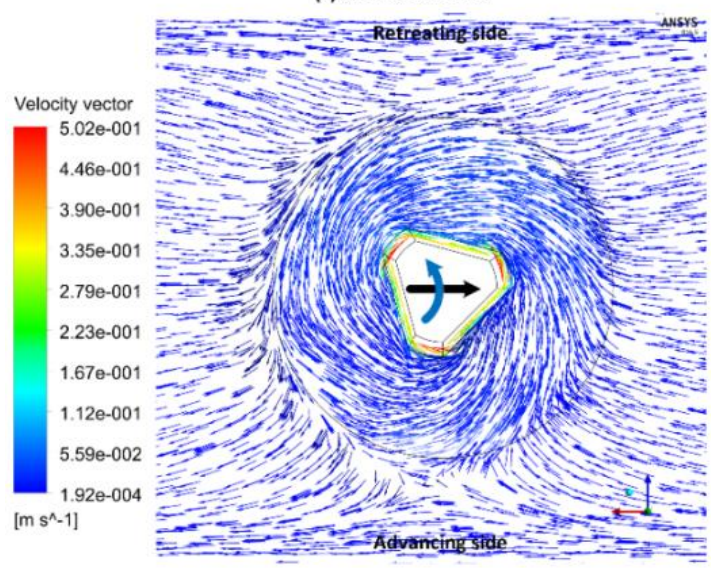

(e) Tapered triflat

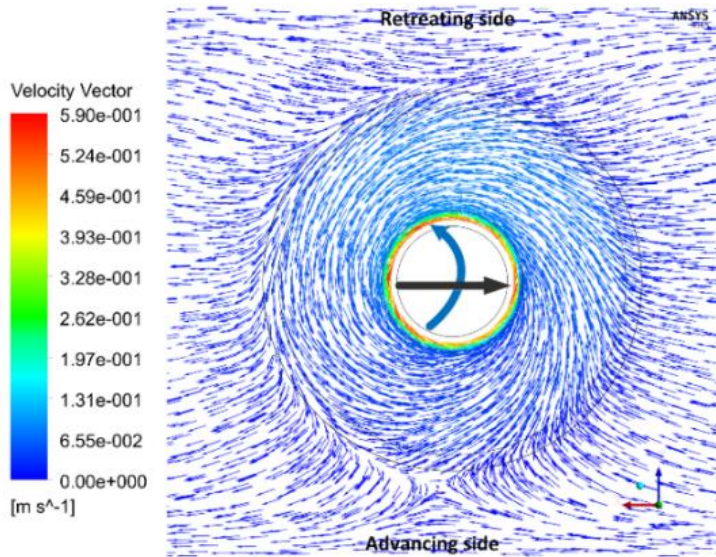

(b) Conical

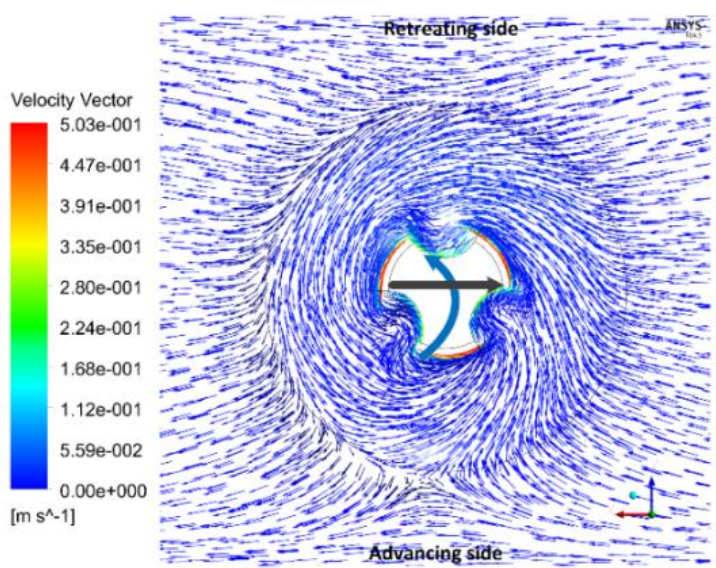

(d) Tapered triflute

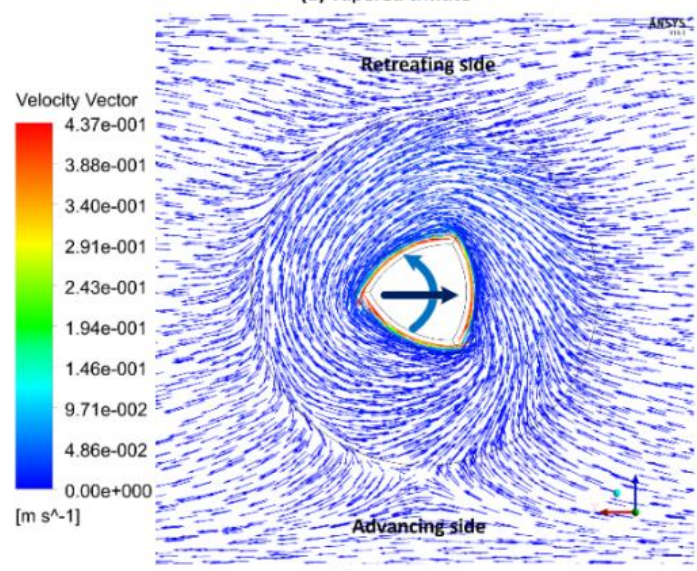

(f) Tapered trivex

Figure 18 Top view of the velocity vector at plane-10 for all tool geometries

It was also seen that flow is smoother in the case of triflat pin than trivex and triflute, as evident from Figure 19 $(d, e$, and f). A more dominating zig-zag wavy travel on pin surface observed in case of triflat pin than triflute and trivex. A larger flow separation zone on advancing side observed in case of the threaded pin as evident from Figure 19 (c) which reflect that better material deposition on trailing side, but at the same time, there was a chance of defect at pin tip bottom due to lack of material flow because of flow separation. 


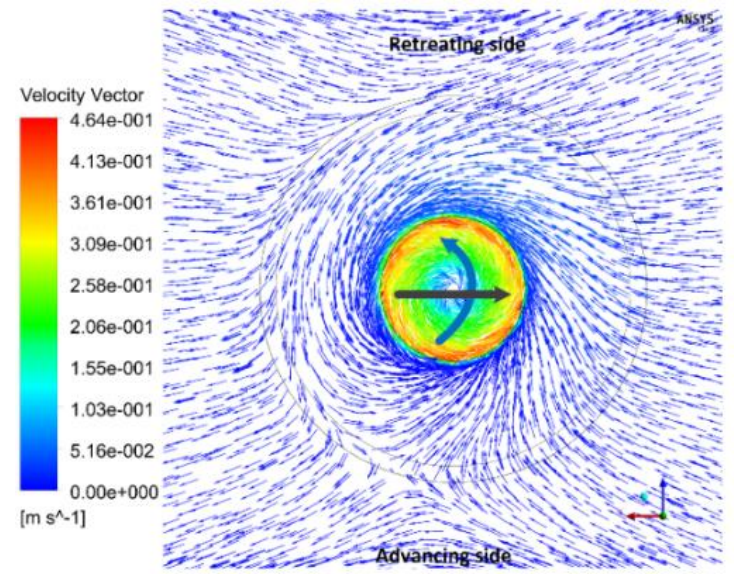

(a) Cylindrica

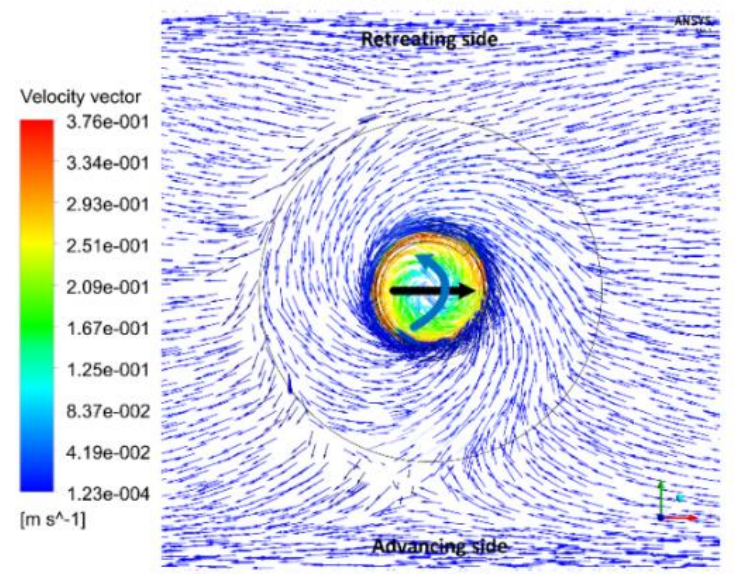

(c) Conical threaded

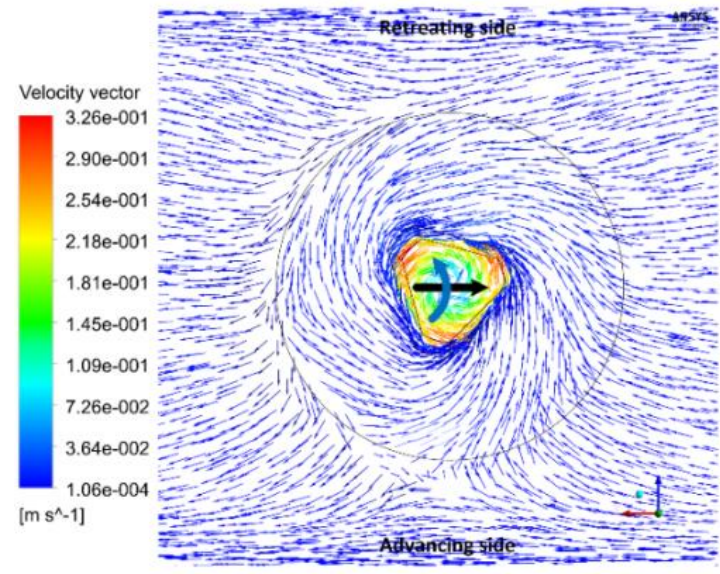

(e) Tapered triflat

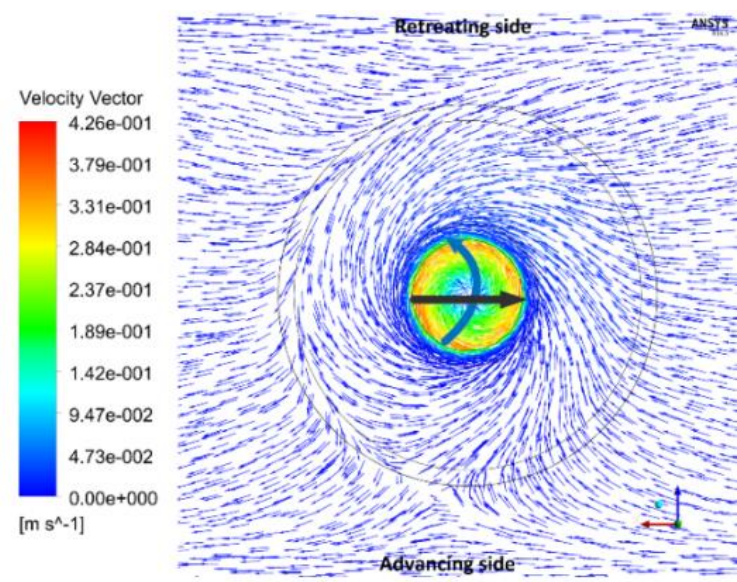

(b) Conical

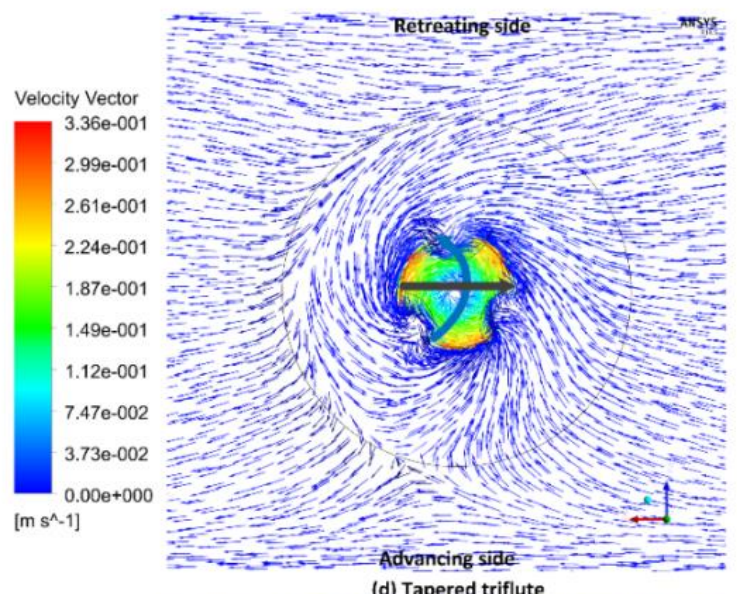

(d) Tapered triflute

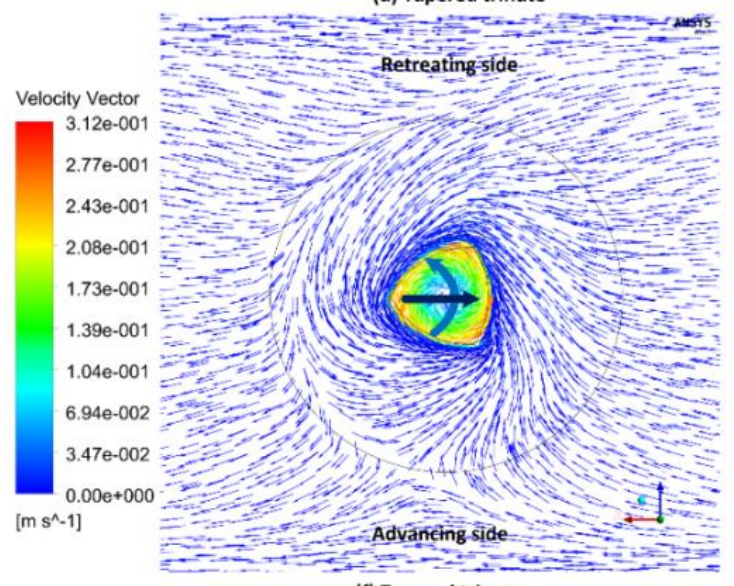

(f) Tapered trivex

Figure 19 Top view of the velocity vector at plane-11 for all tool geometries

Two types of movement were observed in the workpiece around the tool. The movement parallel to the shoulder plane that is along $\mathrm{X}$ and $\mathrm{Z}$ direction and another along with the thickness of the plate, which is along the pin probe axis that is in the Y direction. Both these movements have shown in Figure 20 (a). The material turns smoothly from advancing side to the retreating side when the tool started to move, as evident from the front side in Figure 20 (a). The maximum amount of these deformed materials accumulate in the trailing side to complete the weld, and rest moved ahead. This phenomenon is shown in Figure 20 (a) by separation boundary in the backside. 
On moving away from the probe tip, the deformation zone gradually decreased and observed the smallest near the periphery of the shoulder. Due to the lack of interaction between tool and workpiece in this region, lower temperatures observed. Hence, high viscosity represents a decreased deformation zone. The backside of the rotating tool showed a higher deformation zone as soften material accumulated backside having higher viscosity due to high temperature, as evident from Figure 20 (a).

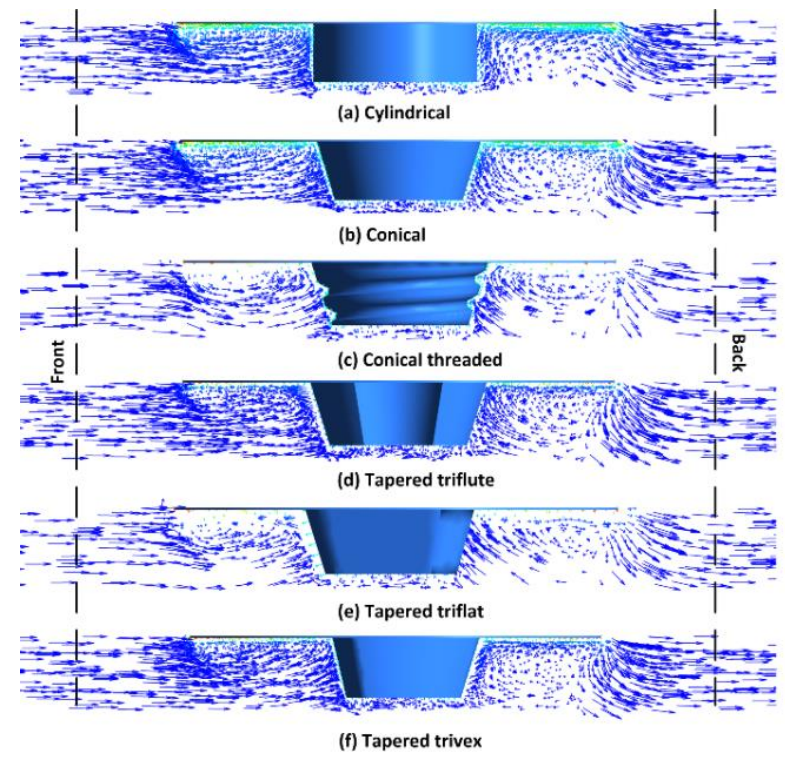

(a)

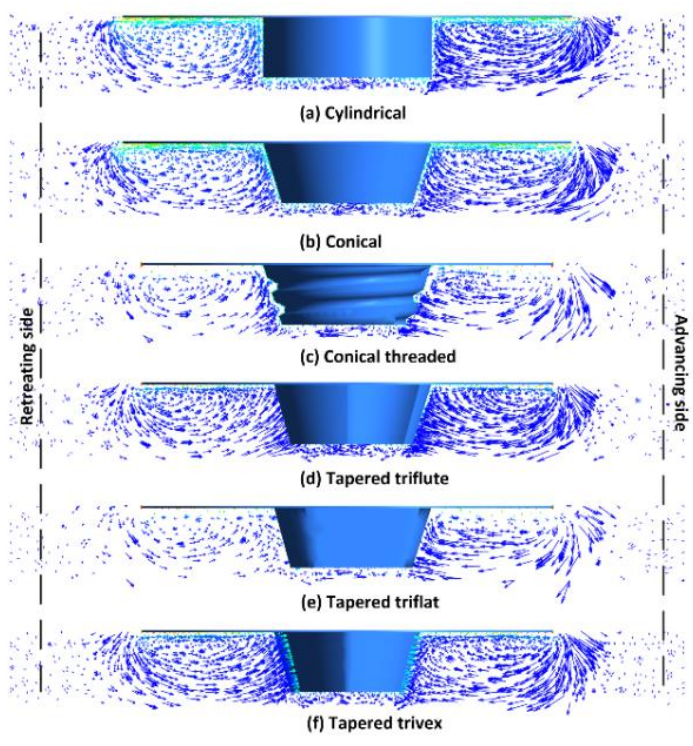

(b)

Figure 20 The vector contour represents the flow of material beneath the tool shoulder around the tool (a) along the $\mathrm{X}$ direction and (b) along the width of workpiece, i.e., at plane-08 for all six geometries

The movement of material flow past over different tool geometries showed different features. There was a similarity noticed in the vector plot in front of the rotating tool. Significant similarity observed the backside of the tool except for the cylindrical one. Material climbs up gradually/smoothly through the tapered pin. This is one of the advantages of the tapered face over vertical face (in case of a cylindrical pin).

RS showed higher deformation as compared to AS around the tool for all geometries, as clearly evident from Figure 20 (b), which greatly affected by tool rotation and traverse direction. AS shows the flow separation having a material deficiency zone, which may lead to a kind of welding defect, but RS shows separation boundaries containing shear layers. Figure 21 (a) showed that material which started rotates initially at advancing-front tried to deposit on the back via retreating-front sliding over the tool (clearly shown in Figure 21 (b)), treating tool as an obstacle. The material moved to the trailing edge, i.e., backside, retreated around the tool to complete the weld.

On advancing side in Figure 21 (b) three types of material flow behavior had observed: (1) Material goes on trailing side on weld line for joining exactly near the tool face; (2) Adjacent from this material some layers of material tried to change its direction at separation line and (3) away from the tool, small vectors show the nondeformed zone. How material slides over tool pin faces for different types of the tool have shown by Figure 21 (a) and Figure 21 (b) for plane-12. 

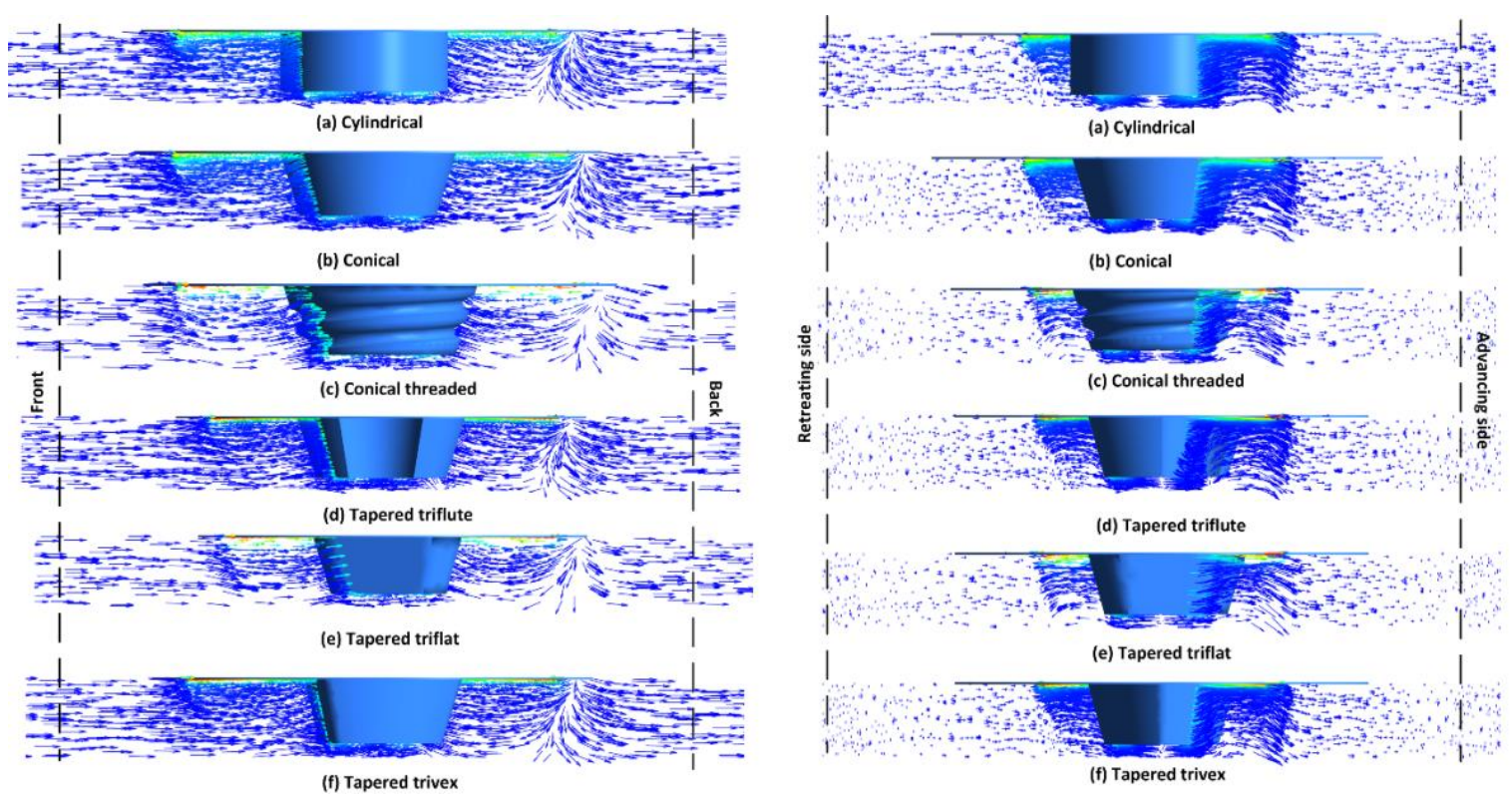

Figure 21 The vector contours representing the flow past around the tool and beneath the tool shoulder (a) on front and back sides (front view of plane-12) and (b) on AS and RS (side view of plane-12) of the tool for all six geometries

When material initially tried to move from the advancing-front region under the tool rotation, a swirl has generated with different origins according to the geometry of the tool pin, as evident from Figure 22 (a). Flow separation line with shear layers formed on the back-retreating zone shown by the backside in Figure 22 (b). Material sliding on tool faces from the retreating side and deposited on the weld line in trailing edge shown by Figure 22 (b). For all planes, front view (along lengthwise) viewing from retreating side and side view (along widthwise) viewing from the trailing edge, i.e., outlet boundaries in numerical case.
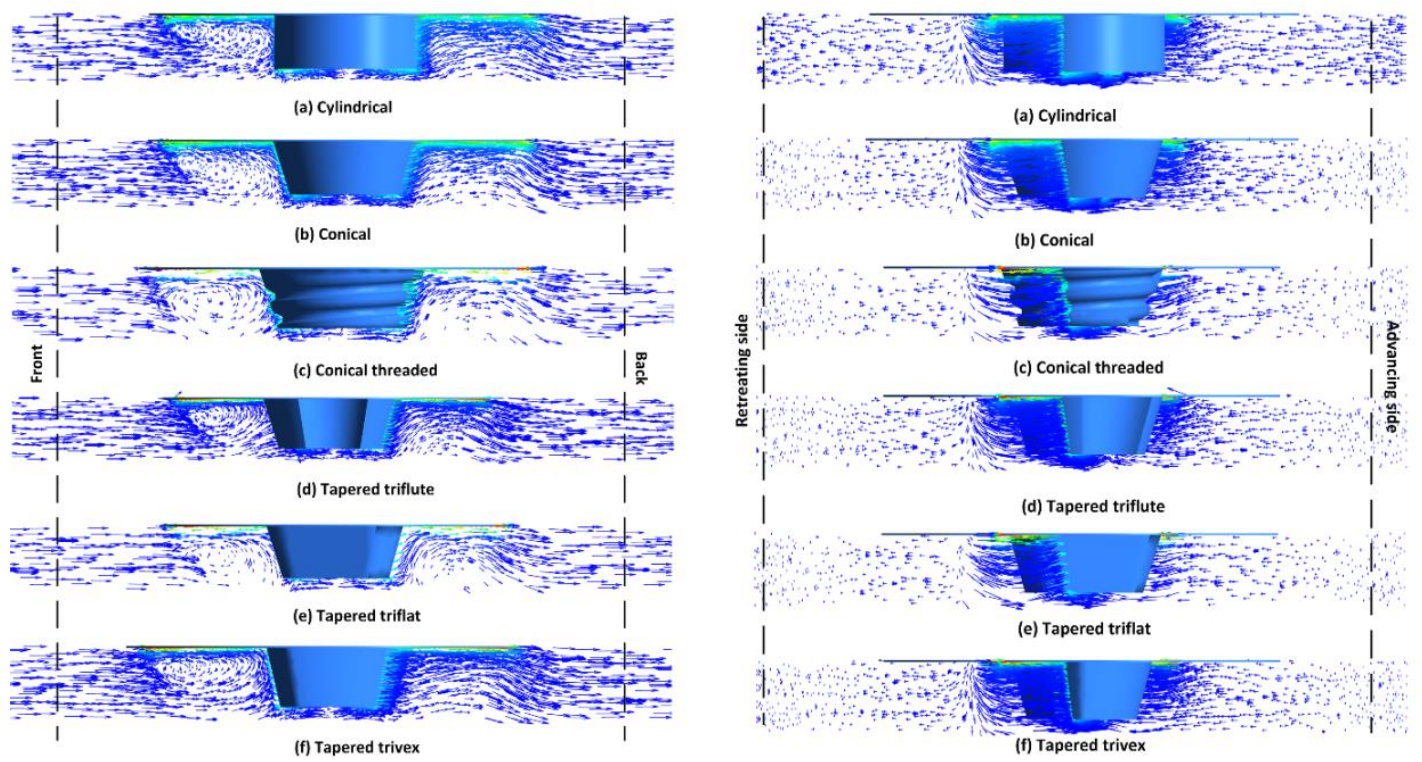

Figure 22 The vector contours representing the material movement beneath the tool shoulder (a) on front and back sides (front view of plane-13) and (b) on AS and RS (side view of plane-13) of the tool for all six geometries

By consideration of tool rotation and tool travel, the material on the AS flow in $-\mathrm{Z}$ direction, whereas the material moves towards $+\mathrm{Z}$ direction on the RS, as evident from Figure 23. It was observed that there were significant 
variations in the maximum and minimum $\mathrm{X}$ velocity, but the distribution of velocities behaves differently with the pin profiles, as evident from Figure 23. A vertical line observed in Figure 23 in all cases showing the separation zone on AS.
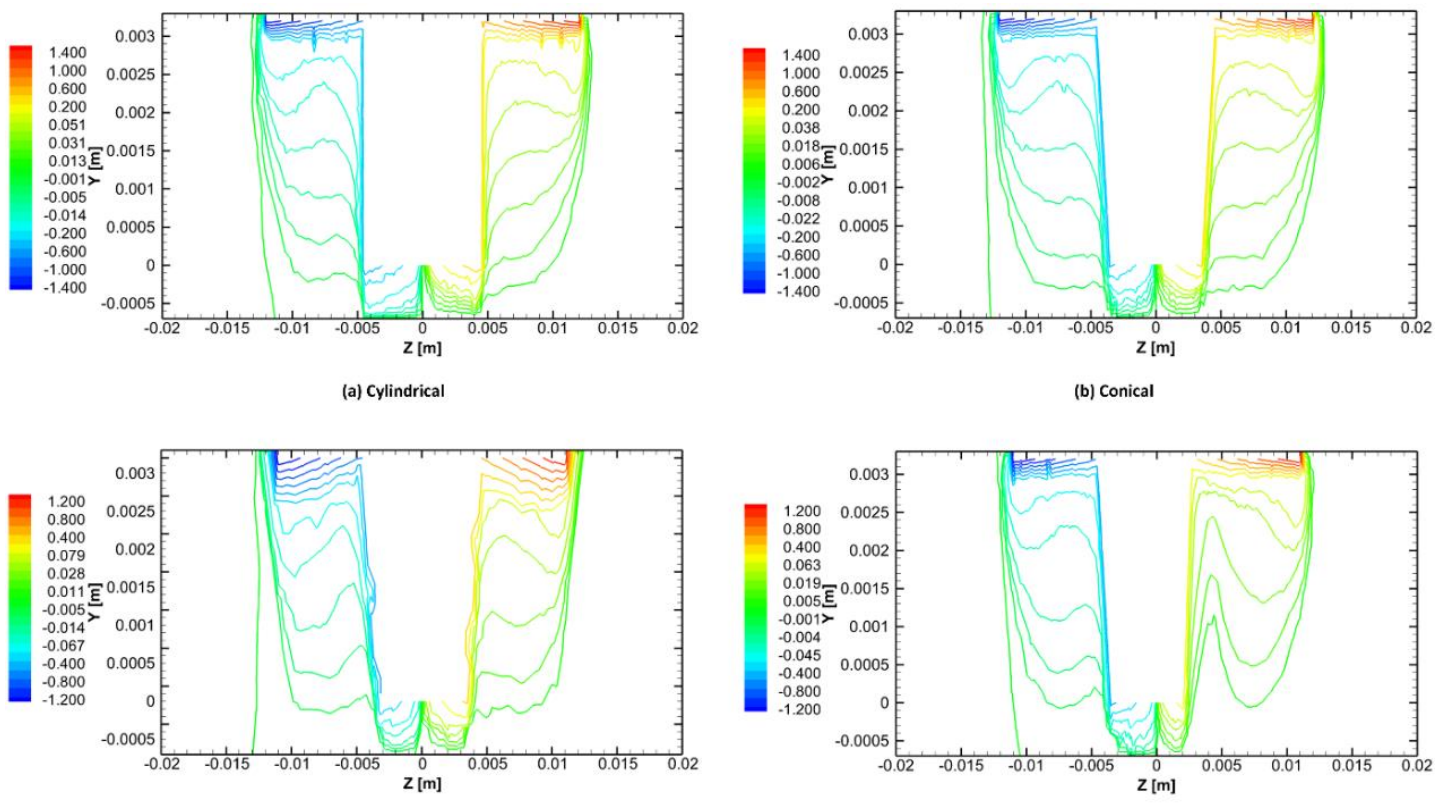

(c) Conical threaded

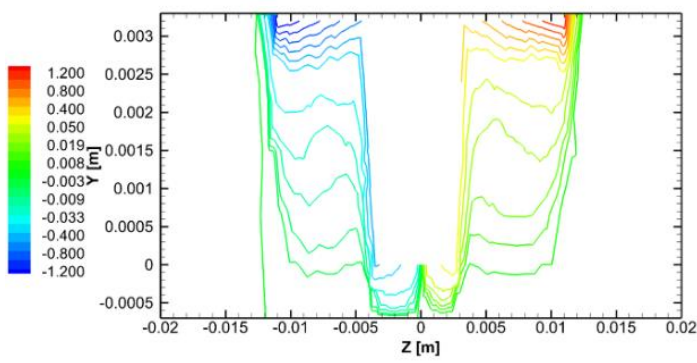

(e) Tapered triflat

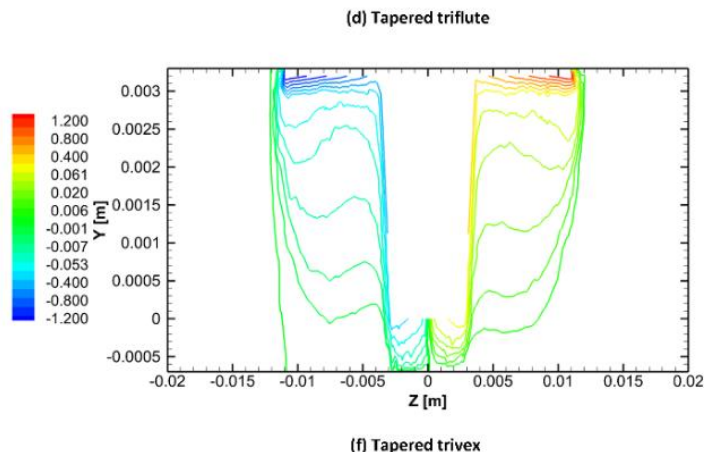

Figure 23 Velocity $(\mathrm{m} / \mathrm{s})$ profiles in the welding direction, i.e., along the $\mathrm{X}$ direction of all six geometries. The velocity distribution shows the RS by $+Z$, whereas, the AS by $-Z$

From the deformation point of view, the higher deformation was created by the cylindrical tool (a) due to its straight pin geometry whereas, triflute represents the lowest deformation zone (d), as evident from Figure 24. The threaded pin (c) showed more deformation area in the AS than a conical pin (b). It was seen that identical profiles obtained for the cylindrical and conical pin on AS but different on RS due to high deformation formed by the cylindrical probe.

Triflute and trivex pin had similar mechanical affected areas, but triflute pin shows different velocity profiles on RS because it faces groove region, i.e., the concave curved surface on the retreating side. The similar profile obtained for conical threaded and tapered triflat pin on AS but a small difference on RS due to flat surface contact with the material in case of tapered triflat pin also uniform deformation observed for both tool in both side, i.e., AS and RS. 

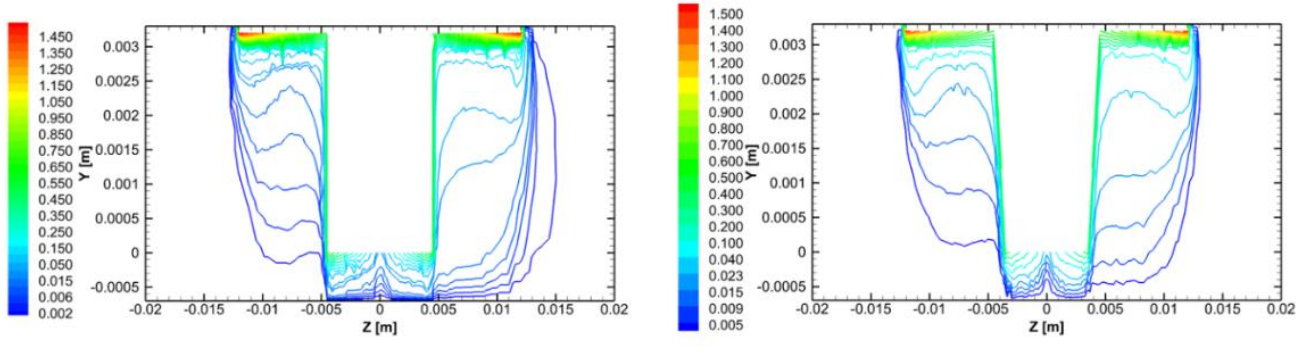

(a) Cylindrical
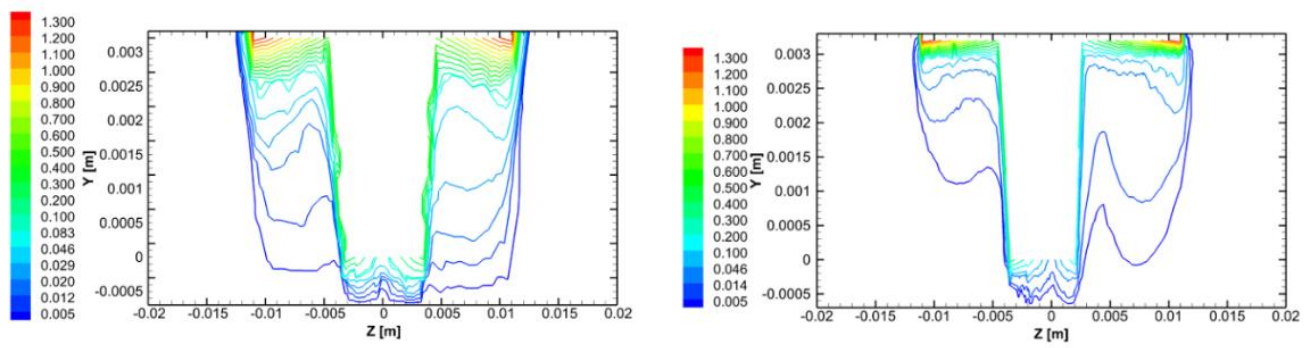

(c) Conical threaded

(d) Tapered triflute

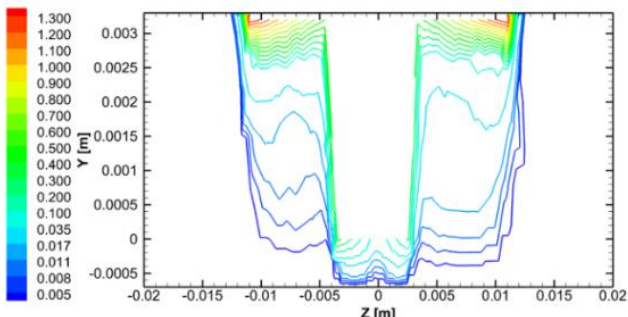

(e)Tapered triflat

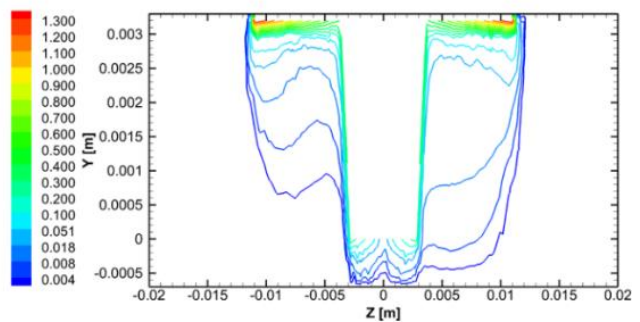

(f) Tapered trivex

Figure 24 Velocity $(\mathrm{m} / \mathrm{s}$ ) magnitude on plane- 08 for all six geometries (RS by $+Z$ whereas, the AS by $-Z$ )

Figure 25 shows the mapping of a simulated streamline with experimentally joined plates. It exhibits that flow governs solely around the shoulder, which reflects the joined section of the workpiece. The material in front of the advancing and rotating tool swept toward the RS and ultimately deposited behind the rotating tool. The closed view of the experimental set-up made after the completion of the welding is shown in Figure 26.

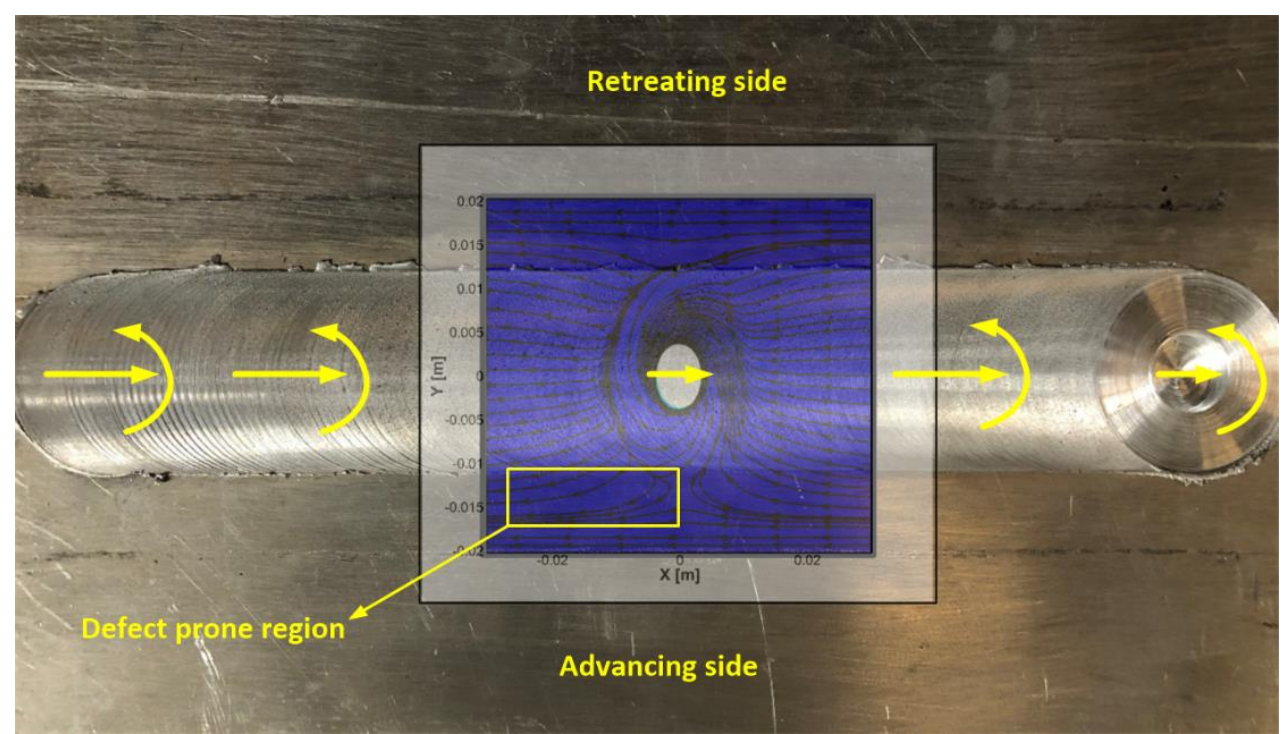

Figure 25 Material flows in the welded region 


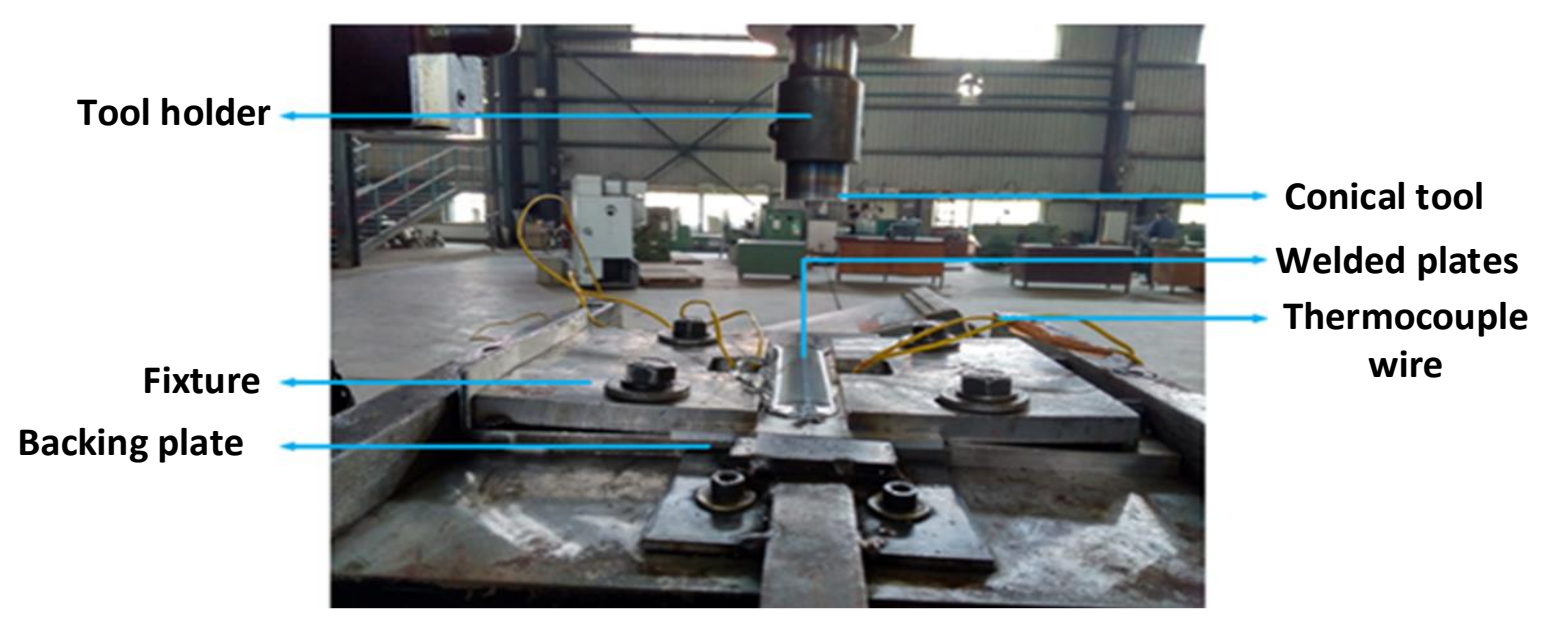

Figure 26 Closed view of experimental set-up (picture taken after completion of weld)

\subsection{Viscosity distribution}

In the FSW process, the temperature is very high near the rotating tool region due to fluid-solid interaction. The main source of heat generation has formed near the tool, and the temperature got decreased as it moved away from the tool. The variation of viscosity studied and shown in Figure 27 for all tool geometries. All contours plotted here in region-02, i.e., for flow capable region having width $36 \mathrm{~mm}$. This variation may come from the dependency of it on temperature and strain rate. Viscosity was found lower at a higher temperature region; hence, velocity was high in that region. Lower temperature region shows the higher viscosity where material moves comparatively at a lower velocity. The minimum viscosity observed near the tool/work interaction region.

\subsection{Strain rate distribution}

Strain rate is directly associated with velocity in all directions. As reported in the vector plot section, rotational effects dominated neat the tool region; hence strain rate was high in that region. On moving radially outwards from the tool axis, the rotational effect got decreased with the lower deformation zone; hence, the lower value of strain rate observed in that region.

The maximum strain rate obtained from the simulation was 1000 1/sec at $1230 \mathrm{rpm}$. The lower strain rate shows the stagnant zone, i.e., boundaries of the workpiece where the flow cannot be possible, and a higher value of strain rate was founded near the shoulder and pin surface. The deformation zone may differ for different types of tool pin used as discussed in the velocity section; hence, obviously, stain rate varies for different types of tool geometry during welding in the workpiece. These variations have shown in Figure 28 along the width of the plate at $0.1 \mathrm{~mm}$ below the pin tip.

Cylindrical tool geometry has the most bigger diameter, i.e., $9 \mathrm{~mm}$ at tool pin tip. Beyond this dimension, the flow effect observed insignificant (Figure 28); hence, the strain rate approaches its lowest value in this region. This is one of the facts that not considering the whole width of the plate on $\mathrm{X}$ coordinate. Due to the larger pin diameter than other, cylindrical pin creates a bigger deformed region with a high strain rate, as evident from Figure 28. 


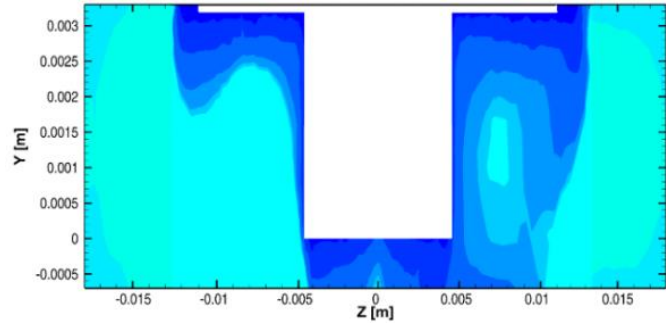

\begin{tabular}{llllll}
\hline $5.74 E-03$ & $1.00 E+05$ & $3.00 E+05$ & $5.00 E+05$ & $7.00 E+05$ & $9.00 E+05$
\end{tabular}

(a) Cylindrical

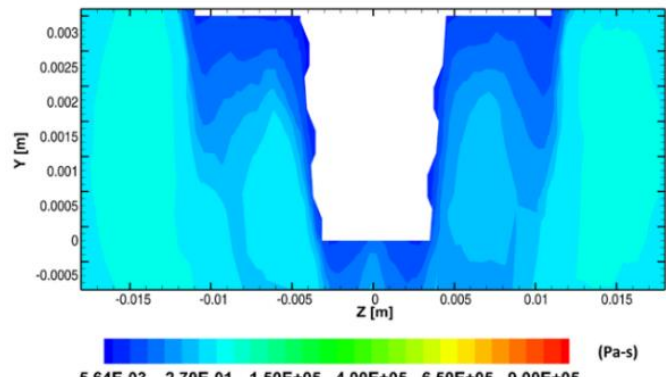

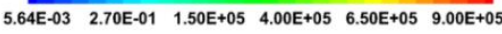

(c) Conical threaded

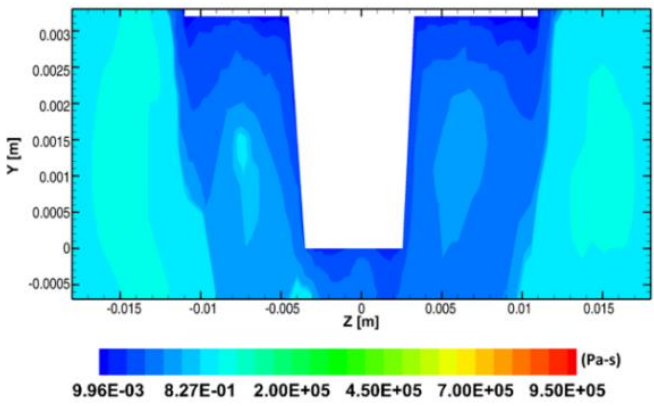

(e) Tapered triflat

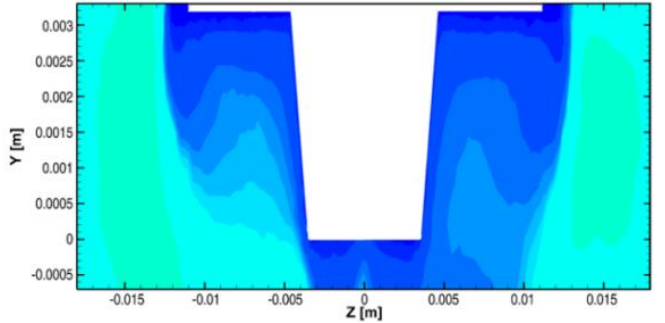

$\begin{array}{llllll}7.46 E-03 & 6.21 E-01 & 1.50 E+05 & 4.00 E+05 & 6.50 E+05 & 9.00 E+05\end{array}$

(b) Conical

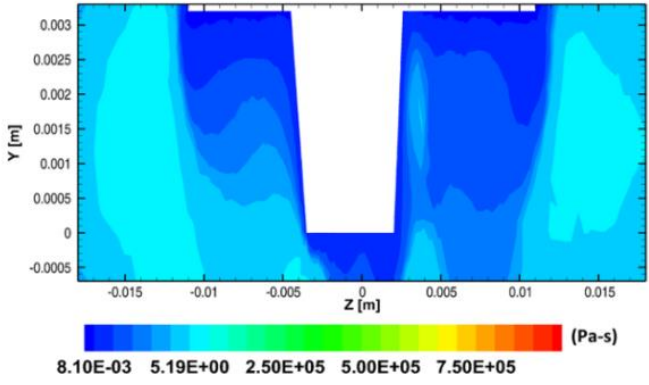

(d) Tapered triflute

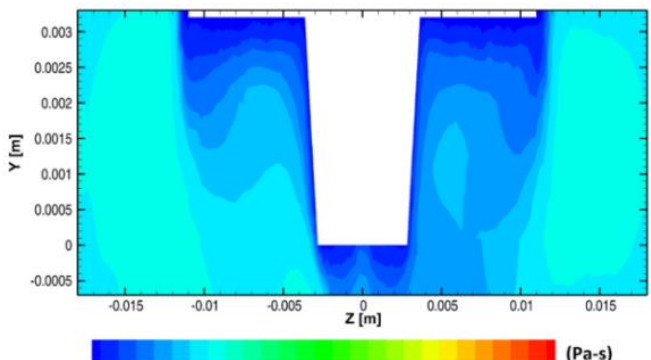

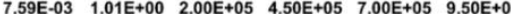

(f) Tapered trivex

Figure 27 Viscosity (Pa-s) contour for different tool pin at plane-08 for $1230 \mathrm{rpm}$

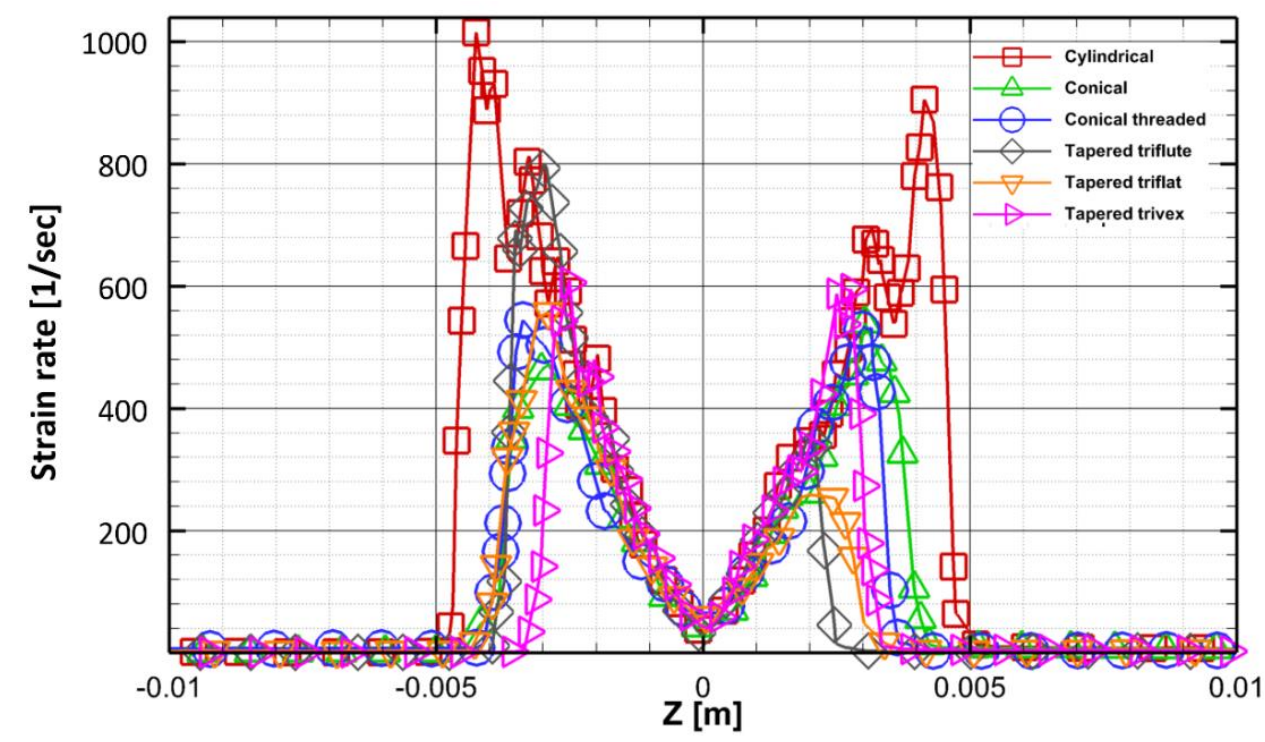

Figure 28 Strain rate for all six geometries along the line which is $0.1 \mathrm{~mm}$ below the pin tip along the width of the workpiece 
It was seen that the strain rate higher for all cases on AS. The reason behind this fact that the material near the tool moves with a high-velocity magnitude and high shearing rate within the AS as compared to the RS, considering the direction of the material flow relative to the tool rotation, that is the plastic strain is higher on the AS than RS, but its magnitudes vary according to tool pin used. Tapered triflat showed the least strain rate on both advancing and retreating sides with a smoother curve, and cylindrical had the highest one. The conical threaded tool showed insignificant differences in strain rate between advancing and retreating sides, which represents the proper mixing of material.

\subsection{Validation of model}

A comparison between experimental and numerical results has been shown in Figure 29. Figure 29 (a) and Figure 29 (b) showed the comparison separately on the advancing and retreating sides, respectively.

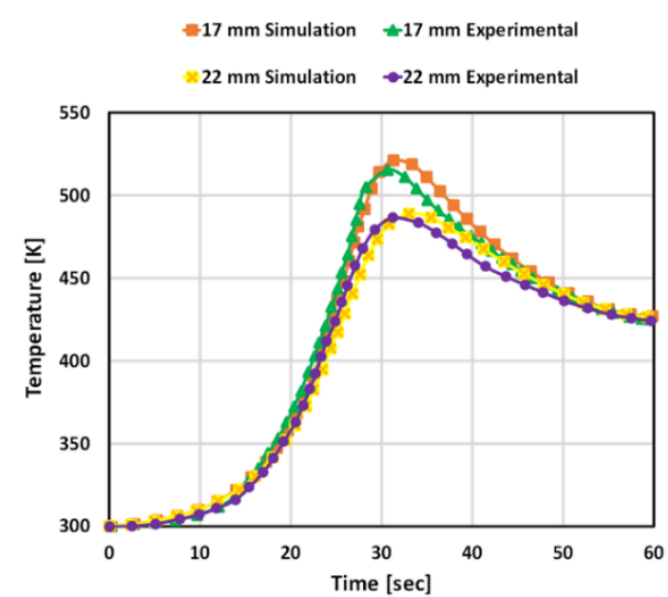

(a)

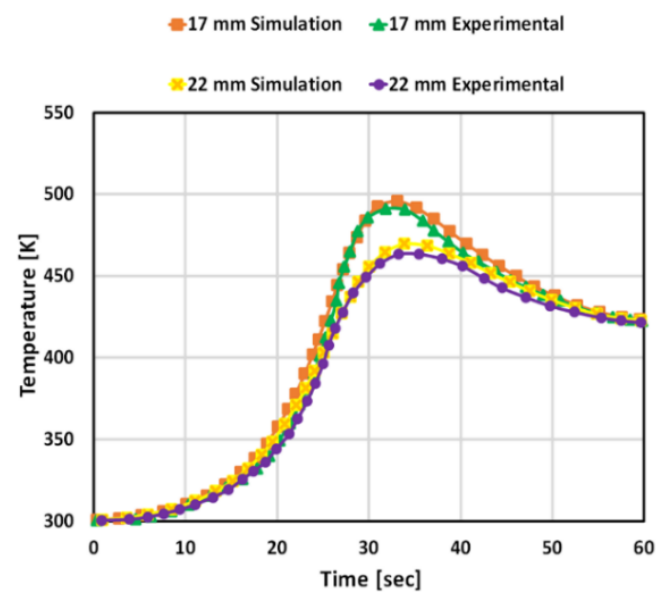

(b)

Figure 29 Comparison of simulated and experimental temperature results on (a) advancing side and (b) retreating side

The model presented in this work has been validated with the experimental results. The experiment was performed on a semi-automatic machine of FSW. The experimental procedure for the validation of the model is shown in Figure 30. Peak temperature obtained in the numerical study was varied compared to the experimental result, but this variation was very small. The rising curve and cooling curve match with a very small deviation. This deviation may come from the assumption taken in this analysis and also due to the heat transfer coefficient is taken for the backing plate.

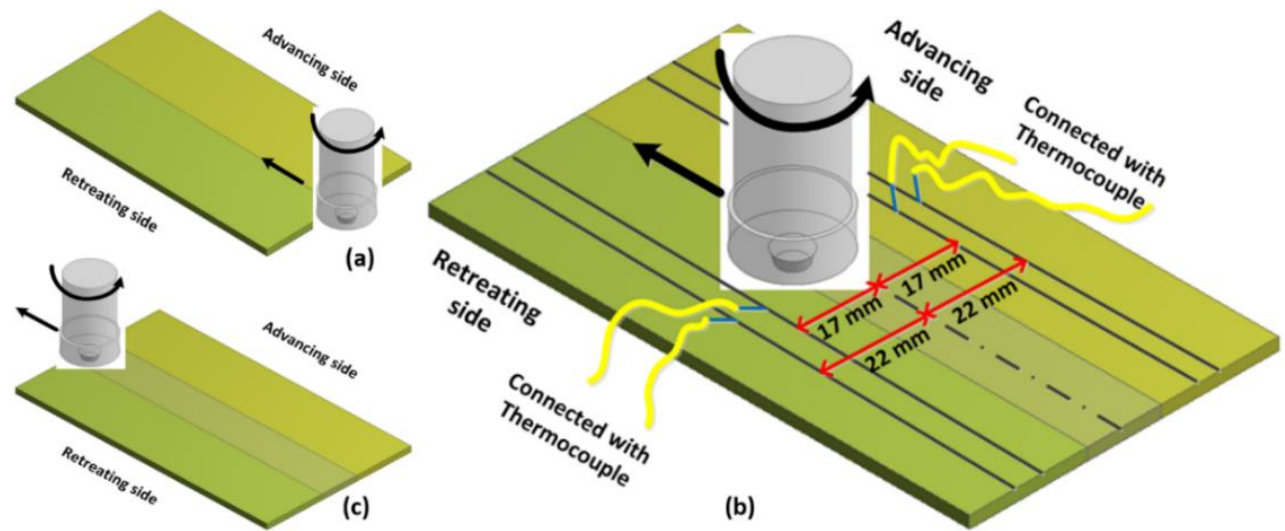

Figure 30 Schematic diagrams of the FSW process and location where thermocouple wire connected 


\section{CONCLUSIONS}

In this work, a full 3-D coupled model was developed. All effort has been made to cast the actual FSW process. The simulated temperature profiles validated with the experimental results. A numerical analysis was performed regarding flow behaviors using different tool pin profile which was difficult to predict experimentally. Based on the result obtained in the present work, the following conclusions could be drawn:

1) An asymmetric distribution observed in temperature profile and maximum temperature observed in that area where higher deformation recognized.

2) The flow of heat was more towards the AS compared to RS.

3) The maximum temperature observed at the shoulder interface in the advancing-trailing side closer to the advancing side.

4) Different tool geometries had a significant effect on heat generation, and it also contributes to deciding the origins of material movement, i.e., swirl inside the workpiece.

5) Peak temperature in the workpiece increased with higher tool rotational speed also more heat transfers at the same time in tool.

6) The strong material flow region observed adjacent to the tool, the material just ahead of the tool turned toward the RS and finally accumulated behind the tool.

7) It was seen that most of the material movement affected by the shoulder of the tool but upward and downward material movement governed by the pin profile.

8) It was seen that higher deformation could be gained from the cylindrical tool than tapered tools with a reasonable and more uniform distribution throughout the depth. The deformed region becomes narrow in tapered tools; therefore, a significant reduction in stirring action near the bottom surface, which could lead to a possible weld defect in this region.

9) Proper material mixing observed with threaded pin and more uniform deformation and viscosity profile observed for tapered triflat pin on both AS and RS. Therefore, the triflat tool can be a better option with threading rather than a conventional cylindrical tool.

10) The analysis performed using a steady-state laminar model produced a satisfactory result and is in good agreement with the experimental result, and obviously, it takes less time compared to the transient model.

\section{ACKNOWLEDGMENTS}

Authors like to thank the Department of Mechanical Engineering, Indian Institute of Technology Guwahati for providing the instruments to complete the experimental work.

\section{FUNDING}

Not applicable

\section{AUTHORS' CONTRIBUTIONS}

All authors contributed equally to this manuscript.

\section{COMPETING INTERESTS}

The authors declare that they have no conflict of interest. 


\section{REFERENCES}

[1] P. Ulysse, “Three-Dimensional Modeling of the Friction Stir-Welding Process," International Journal of Machine Tools and Manufacture, vol. 42, no. 14, pp. 1549-1557, 2002.

[2] K. N. Krishnan, "On the formation of onion rings in friction stir welds," Materials Science and Engineering, vol. A327, p. 246-251, 2002.

[3] M. Song and R. Kovacevic, "Thermal modeling of friction stir welding in a moving coordinate system and its validation," International Journal of Machine Tools \& Manufacture, vol. 43, p. 605-615, 2003.

[4] C. M. Chen and R. Kovacevic, "Finite element modeling of friction stir welding-thermal and thermomechanical analysis," International Journal of Machine Tools \& Manufacture, vol. 43, p. 13191326, 2003.

[5] M. Guerra, C. Schmidt, J. C. McClurea, L. E. Murr and A. C. Nunes, "Flow patterns during friction stir welding," Materials Characterization, vol. 49, p. 95-101, 2003.

[6] P. A. Colegrove and H. R. Shercliff, "3-Dimensional CFD modelling of flow round a threaded friction stir welding tool profile," Journal of Materials Processing Technology, vol. 169, p. 320-327, 2005.

[7] G. Buffa, J. Hua, R. Shivpuri and L. Fratini, "Design of the friction stir welding tool using the continuum based FEM model," Materials Science and Engineering, vol. A 419, p. 381-388, 2006.

[8] P. Heurtier, M. J. Jones, C. Desrayaud, J. H. Driver, F. Montheillet and D. Allehaux, "Mechanical and thermal modelling of Friction Stir Welding," Journal of Materials Processing Technology, vol. 171, p. 348-357, 2006.

[9] H. N. B. Schmidt, T. L. Dickerson and J. H. Hattel, "Material flow in butt friction stir welds in AA2024T3," Acta Materialia, vol. 54, p. 1199-1209, 2006.

[10] K. Elangovan and V. Balasubramanian, "Influences of pin profile and rotational speed of the tool on the formation of friction stir processing zone in AA2219 aluminium alloy," Materials Science and Engineering, vol. A 459, p. 7-18, 2007.

[11] R. Nandan, R. R. Roy, T. J. Lienert and T. Debroy, "Three-dimensional heat and material flow during friction stir welding of mild steel," Acta Materialia, vol. 55, p. 883-895, 2007.

[12] H.-B. Chen, K. Yan, T. Lin, S.-B. Chen, C.-Y. Jiang and Y. Zhao, "The investigation of typical welding defects for 5456 aluminum alloy friction stir welds," Materials Science and Engineering, vol. A 433, p. 64-69, 2006.

[13] M. Riahi and H. Nazari, "Analysis of transient temperature and residual thermal stresses in friction stir welding of aluminum alloy 6061-T6 via numerical simulation," The International Journal of Advanced Manufacturing Technology, vol. 55, no. 1-4, pp. 143-152, 2011.

[14] C. Hamilton, M. Kopyściański, O. Senkov and S. Dymek, "A coupled thermal/material flow model of friction stir welding applied to Sc-modified aluminum alloys," Metallurgical and Materials Transactions A, vol. 44, no. 4, pp. 1730-1740, 2013.

[15] H. W. Zhang, Z. Zhang and J. T. Chen, "3D modeling of material flow in friction stir welding under different process parameters," Journal of Materials Processing Technology, vol. 183, p. 62-70, 2007.

[16] H. Su, C. S. Wu, A. Pittner and M. Rethmeier, "Simultaneous measurement of tool torque, traverse force and axial force in friction stir welding," Journal of Manufacturing Processes, vol. 15, no. 4, pp. 495-500, 2013.

[17] Hao Su, Chuan Song Wua, Marcel Bachmann, Michael Rethmeier, "Numerical modeling for the effect of pin profiles on thermal and material flow characteristics in friction stir welding," Material and Design vol.77, p. 114-125, 2015.

[18]Z. Sun, C.S. Wu, "A numerical model of pin thread effect on material flow and heat generation in shear layer during friction stir welding," Journal of Manufacturing Processes, vol. 36, pp. 10-21, 2018.

[19] Hao Su1, Long Xue, Chuansong Wu1, "Optimizing the tool pin with three flats in friction stir welding of aluminum alloy," The International Journal of Advanced Manufacturing Technology. 